IZA DP No. 8484

Does Early Child Care Help or Hurt Children's Development?

Christina Felfe

Rafael Lalive

September 2014 


\title{
Does Early Child Care Help or Hurt Children's Development?
}

\author{
Christina Felfe \\ University of St. Gallen \\ and CESifo \\ Rafael Lalive \\ University of Lausanne, \\ CEPR, CESifo, NBER and IZA \\ Discussion Paper No. 8484 \\ September 2014 \\ IZA \\ P.O. Box 7240 \\ 53072 Bonn \\ Germany \\ Phone: +49-228-3894-0 \\ Fax: +49-228-3894-180 \\ E-mail: iza@iza.org
}

Any opinions expressed here are those of the author(s) and not those of IZA. Research published in this series may include views on policy, but the institute itself takes no institutional policy positions. The IZA research network is committed to the IZA Guiding Principles of Research Integrity.

The Institute for the Study of Labor (IZA) in Bonn is a local and virtual international research center and a place of communication between science, politics and business. IZA is an independent nonprofit organization supported by Deutsche Post Foundation. The center is associated with the University of Bonn and offers a stimulating research environment through its international network, workshops and conferences, data service, project support, research visits and doctoral program. IZA engages in (i) original and internationally competitive research in all fields of labor economics, (ii) development of policy concepts, and (iii) dissemination of research results and concepts to the interested public.

IZA Discussion Papers often represent preliminary work and are circulated to encourage discussion. Citation of such a paper should account for its provisional character. A revised version may be available directly from the author. 


\section{ABSTRACT \\ Does Early Child Care Help or Hurt Children's Development?}

More children than ever attend center-based care early in life. We study whether children who attend center-based care before age 3 have better or worse language and motor skills, socio-emotional maturity, and school readiness just before entering primary school. In data covering about 36,000 children in one West German state, we use a marginal treatment effects framework to show how causal effects vary with observed characteristics of children, parents, and care centers and with unobserved preferences for center-based care. Early center-based care benefits children with less educated mothers or foreign parents. Benefits increase when parents have a preference for center-based care. Centers with small playgroups and with experienced, trained, or full-time working staff produce the best effects. A modest expansion of the number of places in early care centers improves children's development, whereas a strong expansion has no significant effects.

JEL Classification: J13, I21, I38

Keywords: $\quad$ child care, child development, marginal treatment effects

Corresponding author:

Rafael Lalive

Department of Economics

University of Lausanne

$\mathrm{CH}-1015$ Lausanne-Dorigny

Switzerland

E-mail: Rafael.Lalive@unil.ch

\footnotetext{
*We would like to thank Olof Aslund, Michael Baker, Mark Dusheiko, Maria Fitzpatrick, Eric French, Martin Huber, Steven Lehrer, Patrick Kline, Claudia Senik, Marianne Simonsen, Mark Stabile, Sergio Urzua, Chris White, Ludger Wössmann, and Danny Yagan for valuable comments on earlier versions of this paper. We presented the paper to seminar audiences at Ifo Institute Munich, UC Berkeley, University of Lausanne, University of Mannheim, University of Toronto, CIREQ Montreal, and Barcelona Summer Forum. We are indebted to the MSGWG (Ministry of Social Affairs, Health, Science and Equality) of Schleswig Holstein/Germany who granted us access and further information to their annual reports of the school entrance examinations. In particular, we would like to thank our cooperation partners, Heidrun Thaiss, Ute Thyen and Sabine Brehm for their support and thoughtful input. Rafael Lalive acknowledges financial support from NCCR LIVES; Christina Felfe acknowledges financial support from the Economic Policy Profile Area of the University of St. Gallen. Rafael Lalive thanks the UC Berkeley Center for Labor Economics for its hospitality while rewriting substantial parts of this paper. All remaining errors are our own.
} 


\section{Introduction}

OECD countries differ enormously in the number of children that attend center-based care early in life. Whereas only about 3 or 4 children per 100 attended early care in the Czech and Slovak Republics, almost 66 did so in Denmark in 2010 (OECD, 2014). Former Eastern European and German-speaking countries also have few children in early care, whereas all Nordic countries except Finland are among the highest-ranking countries in early care use. Enrollment in early care has also increased considerably in the past decade: Southern European countries expanded early care by more than 30 percentage points between 2003 and 2010, allowing them to almost close the gap with the Nordic countries. Germany expanded early care more slowly, offering a place in early care to 9 out of 100 children in 2003 and to 23 out of 100 children in 2010.

This paper considers the consequences of attending early care on a child's later development outcomes. Attending high-quality early child care can substantially enhance a child's prospects in life, providing an environment that stimulates communication, creativity, and motor skills. Care professionals at the center can also support parents in identifying developmental problems and can help find strategies for dealing with them. As a result, early care may be an intervention with a very large benefit relative to its cost (Heckman and Masterov, 2007).

However, the effects of attending early care are almost certainly not the same for every child. The quality of the care available at home in comparison to the quality of the care provided by the center shapes the benefits of early care attendance. Children who already benefit from very high quality care at home may not benefit as much from further stimulation at the center if center care functions as a substitute for home care. Alternatively, if home care and center care are complementary, children who are already highly stimulated at home might prosper most. Effects will also differ along unobserved dimensions, such as parents' preferences regarding whether to send their children to care. Understanding whether and how effects vary with preferences is essential from a policy perspective. If selection into care is random, expanding care until every child has access may be worthwhile if early care attendance generates sizeable benefits. Conversely, less than universal access may be a better policy if child care can be provided only to children who stand to benefit most; universal early care costs about 1 percent of GDP.

Our objective here is to provide a detailed assessment of the determinants and the effects of early center-based care on children's development later in life. Our analysis has two novel features. First, we adopt a marginal treatment effect (MTE) framework. The MTE is the average causal effect of early center-based care exposure on child development for children whose parents are indifferent to whether their child is sent to early care (Bjorklund and Moffitt, 1987; Heckman and Vytlacil, 2000; Carneiro et al., 2011). The MTE framework enables us to discuss the full range of heterogeneity in the effects of center-based care exposure on child development. We will particularly highlight how child or family background, center quality, and parents' 
demand for early care affect the MTEs. We also use MTEs to simulate the effects of three reforms of the early child care system: the introduction of center-based care to the average enrollment in our sample (8.4\% enrollment), a further expansion to the current low level in West Germany (20\% enrollment), and a further expansion to $40 \%$ enrollment. Second, we use two new and exceptionally rich data sources: administrative data from school entrance examinations in Schleswig-Holstein, a large West German state, on language skills, socio-emotional maturity, motor skills, and overall school readiness for more than 36,000 children; and information on structural quality features of child care centers to construct a series of quality indicators.

Identification of the MTE requires a continuous instrumental variable (IV). The ideal IV would track exogenous changes in the supply of child care across school districts. Our instrument is the proportion of children attending early child care in each of 335 school districts across three school entry cohorts. This IV works under two conditions. First, early care attendance needs to corresponds to the amount of care in supply. Early care expanded considerably over recent years due to a federal reform in 2005 announcing a future legal right to a place in early care, backed with supplementary federal subsidies. New places were immediately occupied by children due to excess demand: more parents wanted to place their child in early care than could be accommodated. Early care attendance in school districts therefore tracks its supply.

Second, early care attendance needs to be uncorrelated with child development, after correcting for key determinants of child care supply. While these two conditions will not always hold, we find they do in our context. the federal and state governments provided subsidies while offering few guidelines on where they would go. County authorities predicted the demand for early care, which determined the level of subsidies the county received from the federal and the state government, while institutions at the school district level applied directly for subsidies. As a result, the 2005 reform generated substantial variation in the expansion of the early child care system at the school district level. Expansions of early care were not exogenous across school districts: school districts with a high level of female employment and a strong need for additional child care places managed to get them. In addition, expansions often occurred at the cost of care quality. Nevertheless, expansions of child care were exogenous within school districts: once we condition on a set of school district fixed effects, average early care attendance is orthogonal to the socio-economic composition of the school district. Moreover, the composition of children in early care does not change when school districts expand the number of early care places.

Our empirical analysis leads to the following results: First, early child care is particularly beneficial for children with a low socio-economic status (SES), i.e., children whose mothers have had compulsory education only or children of immigrants. Early child care works particulary well for low-SES children whose parents have a high preference for sending their child to early care. Effects for low-SES children are quantitatively important: they are large enough to close the development gap between low and high SES children, or between native and immigrant 
children. Second, centers with smaller playgroups and with older or better trained staff, or with more full-time staff, produce best effects. Effects of early center-based care are downward biased without controls for care center quality. Third, a modest increase in the number of early care places benefits low SES children, whereas a strong expansion has no significant effect. Finally, conventional linear instrumental variables (IV) estimates do not measure the effects of expanding the early care system.

Two main strands of the literature discuss how child care affects children's development. ${ }^{1}$ The first strand investigates the effects of universally accessible child care on children's skill acquisition. A large body of research discusses the effects of non-parental care on pre-school age children (3-6 years old), finding mostly neutral or positive effects (e.g. Berlinski et al., 2009, Cascio, 2009, Dustmann et al., 2013, Felfe et al., 2014, Fitzpatrick, 2008, Gormley Jr. et al., 2008, Havnes and Mogstad, 2011, Magnuson et al., 2007). Research on the effects of nonparental care on younger children (0-2 years old) is less abundant. Focusing on the Canadian province of Québec, Baker et al. (2008) find that lowering the out-of-pocket cost of public child care increases its use but also crowds out existing private care arrangements. While stimulating maternal employment, the child care subsidy led to more negative parenting styles, resulting in a deterioration of child well-being. Datta-Gupta and Simonsen (2010) find that Danish children benefit more from center-based care than from lower-quality informal day care. Noboa Hidalgo and Urzúa (2012) find short-term gains from center-based care targeted at Chilean children aged 5-14 months, particularly in terms of motor and cognitive skills.

The second strand of the literature focuses on understanding the consequences of maternal employment on children's achievement. This strand is relevant for our study, as center-based care represents the main care mode for working mothers. Maternal employment can improve intellectual performance by increasing household income (Blau and Grossberg, 1992) but may also negatively affect children's cognitive outcomes (Baum, 2003; James-Burdumy, 2005), depending on certain characteristics of mothers and families (see Ruhm, 2004, and Brooks-Gunn et al., 2002, for an overview). Several recent studies exploit changes in time spent with parents due to reforms in the length of parental leave to assess the role of time with parents in children's long-term development. Wuertz-Rasmussen (2010), Liu and Skans (2010), Baker and Milligan (2012), and Dustmann and Schoenberg (2012) find no effects, whereas Carneiro et al. (2014) detect some positive long-term effects on educational attainment and labor market outcomes at age 25 in Norway.

Our analysis complements the existing literature in at least three respects. First, to the best

\footnotetext{
${ }^{1} \mathrm{~A}$ further, related strand focuses on the effects of pre-school interventions targeting disadvantaged children. These targeted interventions have demonstrated strong beneficial impacts on the development of participating children; see Blau and Currie (2006) or Heckman and Masterov (2007) for an overview. We do not review the literature on targeted interventions, since their effects are likely to differ from the effects of providing universal child care.
} 
of our knowledge, this is the first study estimating MTEs of early center-based care on children's development. ${ }^{2}$ This framework allows us to discuss the full range of heterogeneity in the effects of early center-based care exposure with respect to observed background characteristics as well as to unobserved determinants of access. This information is critical for policy since it singles out the conditions under which children benefit more (or less) from center-based care. Second, existing studies of the effects of center-based care on child outcomes typically lack information on the quality of available care centers. ${ }^{3}$ Our analysis uses detailed information on the quality of available care centers and shows that quality is a very important determinant of the returns on center-based care exposure. Third, we provide an assessment of how alternative reforms that expand the number of places in care centers affect the children who gain access because of these reforms. Finally, we discuss how these policy simulations compare to linear IV estimates, the dominant estimation framework in the existing literature.

The next section provides background on early child care and the school entrance examination in West Germany and specifically in Schleswig-Holstein, the region that we studied. In addition, it outlines our hypotheses about the effects of early child care on children's development. Section 3 presents the data and provides a descriptive analysis. Section 4 presents the conceptual framework of our analysis. Section 5 contains the main results of our analysis, and section 6 offers some conclusions.

\section{Background}

\subsection{The Child Care System in Germany}

Germany offers child care at two levels. ${ }^{4}$ Early child care is available for children aged 0 to 2 years, while later child care - kindergarten —is available for children aged 3 to 6 years. Every child aged 3 to 6 years has been legally entitled to a place in kindergarten since 1996. As a result of this policy, around $90 \%$ of all children aged 3-6 years attend kindergarten in SchleswigHolstein, with very little variation across school districts.

Child care centers are in charge of offering early child care. Centers have a clear educa-

\footnotetext{
${ }^{2}$ Studies concerned with the distributional effects of child care programs have so far only relied on quantile regressions approaches (Bitler et al. (2013) study Head Start; Havnes and Mogstad (2014) study child care in Norway). A recent government report by Bucarey et al. (2014) studies heterogeneity in the observed and unobserved determinants of the propensity to participate in public child care. MTEs have been studied in other settings. Doyle (2007) measures MTEs of foster care on child outcomes. Maestas et al. (2013) and French and Song (2014) estimate MTEs of disability benefit receipt on labor supply. Brinch et al. (2014) extend the MTE framework to a setting with multiple discrete instruments. A previous version of this paper, Felfe and Lalive (2012), attempted to estimate MTEs of center-based care on contemporaneous child development outcomes using information from the German Socio-Economic Panel (SOEP). These short-term MTE estimates are very imprecise due to the small number of observations available in the SOEP.

${ }^{3}$ Walters (2014) provides a recent analysis of the relevance of center quality for explaining the variation in Head Start effectiveness across Head Start centers.

${ }^{4}$ This section draws on Huesken (2010).
} 
tional mission to develop children's motor, language, and pattern-recognition skills. Center staff supports the development of these skills by engaging children in playful activities. In addition, social interactions between the child and staff and with other children in the center contribute to the development of social skills.

States (Bundesländer) are in charge of regulating the quality of center-based care in Germany. Regulations concern aspects such as opening hours, group size, and staff-child ratios as well as staff qualifications. Care centers have to remain open for at least four hours five days per week. Playgroups can have at most ten children and need to be supervised by at least one certified education specialist and one or two assistants. The degree required to work as a group leader in a child care center requires two years of theoretical training and at least two years of practice in a child care center. Care centers comply with these regulations: in 2006 and 2007 groups accommodated on average 10.2 children, $62.3 \%$ of the employed staff had a degree in early childhood education, and the ratio of children to staff was about 3:1.

Center-based care is run by subsidized nonprofit organizations. In 2006, public subsidies paid for about $78.9 \%$ of the total cost of center-based care, whereas parents contributed $14.0 \%$, and other private organizations contributed $7.1 \%$ of the total operating cost of 14.1 billion Euros. Fees depend on family size in a regressive manner and on income in a progressive manner and range from 0 to 600 Euros per month. Thus, centers offer high-quality and low-cost care for young children.

Many parents who want to place their children in center-based care cannot do so because of supply shortages in West Germany. For instance, Schleswig-Holstein offered 2.6 places per 100 children aged 0 to 2 years in 2002. Centers use waiting lists to allocate places to families who sign their children up early. ${ }^{5}$ Children whose parents are both working, children living with a single parent, or children who have previously enrolled siblings receive preferential treatment.

What explains the excess demand for center-based care? And why is there no private market satisfying this demand? The child care market is highly regulated. Thus, opening a child care center entails large costs. Parents, however, pay a price that is well below marginal cost, due to generous subsidies. Parents are unwilling to bear the full cost of a slot in a care center for three reasons. First, Germany offers a rather generous parental leave system. Since 1992, parents have been able to claim parental leave benefits of up to 450 Euros per month for up to 24 months after childbirth and enjoy a job guarantee for up to 36 months after childbirth. ${ }^{6}$ Hence, parents do

\footnotetext{
${ }^{5}$ There is quite strict zoning for child care. Parents can apply for a place in a school district where they do not live, but they do not have any right to subsidies and their child is served last. This system effectively rules out any incentive for parents to sign their child up outside the school district of residence. One might think that such a system would encourage migration. Yet investigating cross-county migration patterns around childbirth and the first years thereafter, we find that few parents move and that mobility decisions are unrelated to the number of places offered by counties.

${ }^{6}$ The parental leave system has changed recently. Parents of all children born after January 1, 2007, are entitled to $67 \%$ of their last monthly net earnings for a period of up to 12 months after childbirth. The recent reform, however, did not affect the parents of the children we studied in the empirical analysis.
} 
not face any threat of job loss over a period of 3 years after childbirth. Second, women work in occupations with a rather flat wage profile and face lower opportunity costs of interrupting their careers after childbirth (Felfe, 2012). Finally, traditional views of parental roles are still present in West Germany: parents who do not take care of their children themselves are frequently referred to as "raven parents," and judgment is even more severe if parents have their children taken care of by an unlicensed caregiver. As a result, mothers primarily use center-based care during work hours. Only $2.1 \%$ of all families use informal care on a full-time basis. ${ }^{7}$

The German government enacted a day care expansion law to deal with the severe shortages of early care (Tagesbetreuungsausbaugesetz). This 2005 mandate triggered a strong expansion of child care for children aged 0 to 2 years. The objective of this law was to make early child care universally accessible by 2010. This objective was reinforced in a law on support for children (Kinderförderungsgesetz) in December 2008, when the German government announced that all children aged 1 year and older would be entitled to a child care place by August 2013. As a consequence, child care availability increased substantially over the subsequent years. In Schleswig-Holstein, for instance, 5.5\% of all children born between July 2002 and June 2003 attended center-based care before turning 3 years old; this percentage increased to $7.5 \%$ among children in the birth cohort 2003/2004 and to $12.5 \%$ among children in the birth cohort $2004 / 2005$.

How regions expand early care is crucial for our empirical analysis. The process has four steps. First, county authorities assess the demand for child care each year based on current cohort size as well as economic conditions such as female employment, GDP per capita, unemployment, and net migration. In a second step, the federal and state government endow county authorities with a certain amount of funding depending on the projected demand for child care. Third, non-profit organizations directly submit their proposals to expand existing centers or to set up new centers. Fourth, authorities at the county level assess proposals and approve or reject them. Centers need approval by the county authority to receive subsidies.

\subsection{School Entrance Examination}

Children undergo several mandatory medical screenings in Germany. These medical screenings are meant to document children's health, diagnose medical anomalies, and provide necessary treatment as early as possible. An important medical screening is the school entrance examination (SEE). A pediatrician employed by the local health service examines every child in the year prior to entering primary school in the context of the SEE. Besides documenting a child's health, the focus of this examination is to determine whether a child is "ready" to follow the school curriculum or not.

\footnotetext{
${ }^{7}$ We provide a detailed analysis of time allocation of mothers of children aged 2 to 4 years in a previous version of this paper (Felfe and Lalive, 2012).
} 
Pediatricians assess children's state of development with regard to language skills, motor skills, and socio-emotional maturity in the form of a medical diagnosis. ${ }^{8}$ The language skills assessment concerns articulation, expression of thoughts, and problems with hearing. Children describe a story presented in pictures and repeat several pseudo-words and sentences. The motor skills diagnosis concerns coordination and motor capacity. Children have to stand on one leg, jump on one leg, and jump left and right. The socio-emotional maturity assessment is based on the pediatrician's observations as well as on a questionnaire designed to identify emotional problems, behavioral problems, hyperactivity, peer relationships, and social behavior toward the accompanying caregiver (Goodman, 1997). ${ }^{9}$

The school readiness assessment evaluates whether a child is ready for school or not. This assessment is correlated with the medical diagnoses, but the correlations need not be perfect. Pediatricians weigh the diagnoses concerning language, motor, and socio-emotional skills differentially, and they include further aspects, i.e., proficiency in German or cultural assimilation for immigrant children. The school readiness diagnosis is an important piece of information regarding school enrollment, but it is not binding. It is ultimately up to the parents to decide whether to enroll their child in school or not.

\subsection{Hypotheses}

Attending early care might help or hurt children's development for two reasons. First, centerbased care replaces some of the hours of care provided by other sources (mother or father, extended family, or informal caregivers). Felfe and Lalive (2012) document who provides care for children who do and do not attend early care in the West German context. Their analysis shows that children who attend early care spend less time with their mothers. Nevertheless, mothers who rely on early care continue to perform cognitively stimulating activities with their children, such as reading or singing songs, while cutting down on more passive activities, such as shopping or watching TV. Center-based care thus increases the average quality of care provided by the mother by replacing activities least conducive to child development. Second, center-based care frees up time for the mother to go back to work, thereby increasing household income. Increased family income contributes to children's development (see, for instance, Dahl and Lochner, 2012, Gonzalez, 2013, or Black et al., 2014).

Given that center-based care and maternal care are alternatives, the causal effects of attending early care depend on the quality of maternal care, for which the socio-economic background

\footnotetext{
${ }^{8}$ The diagnosis can take five forms: "negative, no problems," "positive, but no treatment is necessary," "positive, already in treatment," "positive, treatment necessary," and "positive, problem will reduce the child's performance in school."

${ }^{9}$ The assessment of socio-emotional maturity might be affected by subjective perceptions of the caregiver or by nonresponse problems. Considering that the pediatrician reassesses children's socio-emotional maturity and that in $93 \%$ of all cases a medical diagnoses regarding socio-emotional maturity is available, reporting bias and nonresponse bias are not a major concern in our context.
} 
of the mother serves as a proxy. ${ }^{10}$ However, it is not clear how higher quality maternal care should correlate with the effect of center-based care. Center-based care could be a substitute for maternal care, in which case low-SES children could reap large benefits, whereas high-SES children might not benefit much or may even be hurt. Alternatively, center-based care could be a complement to maternal care. For instance, a child who has learned to sit still by listening to stories at home might learn to draw more easily in the care center than a child who cannot follow drawing instructions because he or she has not learned to sit still yet. In that case, center-based care could be more advantageous for high-SES children than for low-SES children. We will analyze in detail how the effects of early center-based care differ across children's SES.

Returns on attending center-based care might also vary with parents' preferences for sending their child to early center-based care. Parents could base their decision to send their child to early care on the benefits their child might experience, as Roy (1951) has argued in another context. Yet, the decision to use care could also be based on other aspects, including potential gains to the entire household. We will study below whether selection is based on gains to the child or on other features. Understanding the selection process and how returns on early care relate to the selection process is crucial from a policy perspective.

We study whether attending child care before age 3 affects child development at the age of about 6 , just before entering primary school. Center-based care might affect children's development beyond age 3 because early success can help build non-cognitive skills such as selfconfidence and curiousness. Children who acquire these cognitive and non-cognitive skills early can progress to learning more demanding tasks. Earlier research suggests that the effects of educational interventions can be long lasting. For instance, studies of the STAR project, a setting very similar to ours, find that the effects of attending a small class during kindergarten and primary school remain positive and substantial once children have progressed into middle school and later in life (Chetty et al., 2011; Krueger and Whitmore, 2001). Second, the reanalysis of the Perry PreSchool Program by Heckman et al. (2010) documents very long lasting benefits of this targeted pre-school intervention. But whether access to early care generates similarly durable effects remains an open question.

\footnotetext{
${ }^{10}$ There is a well-established body of literature that demonstrates educational disparities in parenting practices. For example, better-educated parents provide more cognitive stimulation at home (Davis-Kean, 2005; Linver et al., 2002; Yeung et al., 2002) and are better at delegating activities that do not stimulate children's development (Hsin and Felfe, 2014). We therefore use mother's education as a proxy for quality of maternal care. In addition, we stratify with respect to children's ethnic background, as foreigners are likely to stem from a lower socio-economic background in Germany (Algan et al., 2010).
} 


\section{Data and Descriptive Analysis}

\subsection{Data}

Administrative records from Schleswig-Holstein's school entrance examinations (SEE) are our main data source. The data are structured by school entrance cohort. A school entrance cohort comprises all children who turn 6 years old between July of the previous year and June of the year of school entrance. ${ }^{11}$ SEE data contains medical assessments of language and motor skills, socio-emotional maturity, and school readiness provided by pediatricians. In addition, it contains family background information such as parental education, immigrant status, etc. reported by the accompanying caregiver.

The data do not contain direct information on whether a child attended early care or not. Parents provide information on the years of center-based care attendance. ${ }^{12}$ This information is rounded upward, i.e., parents of a child who has attended center-based care for 2.5 years report a duration of 3 years. We construct a classification of early care attendance as follows: We assume that children start center-based care or kindergarten on their birthdays. This assumption is plausible in the legal setting of Germany, where changes in parental leave and parental benefits occur around the child's birthday. We then calculate the number of months children have attended center-based care at the age of 6 years. We classify children with at least 36 months of center-based care as having attended early care. About $8 \%$ of all children in our sample attended early care according to this classification, a figure that closely matches official statistics on early care attendance.

Our early care classification implies that children slightly younger than 6 years are more likely to be classified as having attended early care than children slightly older than 6 years. For instance, consider a child who is 5 years and 11 months old at the SEE date and has attended center-based care for 3 years. We will consider this child as having attended early care, since he or she will have had 36 months of center-based care exposure at the age of 6 years. However, we would not consider the same child to have attended early care if he or she had been 6 years old on the month of the interview. We correct for this feature of our classification by controlling for the age of the child.

The SEE is organized by school district, the catchment area of schools. School districts correspond either to a collection of several small municipalities or to part of a large municipality (e.g., a city). We observe the school district of the place of residence of a child at the SEE date.

\footnotetext{
${ }^{11}$ Children who are not ready for school in a given year take a special examination the following year and thus are not included in the baseline SEE. Parents whose child turns 6 years old between July and December of the same year can ask their child to be examined a year before the official SEE would have taken place. We assign children to the original birth cohort to deal with the endogeneity of early assessment.

${ }^{12}$ We have no individual information on the intensive margin, the number of hours of early care attendance for each child. We will use information on the proportion of children attending a center full time at the county level to assess the relevance of the intensive margin.
} 
As post-birth mobility is low in West Germany, the school district of residence at the SEE date is likely to be the same as the school district of residence when the child attended early care for most children in our sample. Our data contains identifiers for 335 school districts located in 10 out of the total of 15 counties in Schleswig-Holstein. Our analysis considers children who live in school districts with at least 5 children per school entrance cohort because we construct school district-level information by aggregating individual information.

We merge detailed information on the quality of child care centers by county and school entrance cohort to the SEE data. We use three types of information. First, we know the number of children that are allocated to a playgroup, a proxy for the child-staff ratio. Second, we have information related to the average quality of care per staff member: staff age, the proportion of staff with a degree in child education, and the proportion of staff working fulltime. Third, we observe the proportion of children in full-time care, a proxy for the number of hours in center-based care. This information allows us to assess whether the number of hours spent in early care, the intensive margin of early care attendance, matters.

There are two issues with center quality data. First, our data provide measures of the average quality of care, yet care center quality might vary within counties. Our approach identifies a lower bound on the relevance of care quality in case quality differs substantially within counties, but the within-county variation should be limited, since counties are in charge of controlling state-level regulations. Second, data on care center quality is only available from 2006 onwards. We use center-quality information from 2007 for the 2011 SEE cohort and centerquality information from 2006 for the 2010 SEE cohort, and we impute quality for the 2009 SEE cohort using center-quality information from 2006.

\subsection{Descriptive Statistics}

Figure 1 shows the proportion of children without any developmental problems, by age and development outcomes. The proportion of children without developmental problems increases from about $60 \%$ to $70 \%$ among children who are 5.5 years old to a level of between $80 \%$ and $90 \%$ among children who are 6.5 years old across all development outcomes. Children who attended early care before age 3 are less likely to show a developmental problem just before entering primary school. This advantage is sizeable for language skills and school readiness and it is also visible for motor skills and socio-emotional maturity.

Table 1 provides descriptive statistics for the estimation sample, by early child care status. About $8.4 \%$ of all children had some exposure to early care. Specifically, 3,047 children attended early center-based care. We refer to these as treated children. 33,334 children were not exposed to early center-based care. We refer to these as control children.

Panel A of Table 1 provides information on child development. About $79 \%$ of treated chil- 
dren and $75 \%$ of control children do not have any problems in the area of language. Also, $89 \%$ of treated children and $86 \%$ of the control children are ready for school. Developmental differences in language skills and school readiness are significant at the $1 \%$ significance level. Differences are less pronounced for socio-emotional maturity and motor skills and are not statistically significantly different from zero at the $5 \%$ level.

Panel B in Table 1 reports information on the characteristics of children. Boys and girls are equally frequent among treated and control children. Treated children are about one month younger than control children (6 years and 1 month versus 6 years and 2 months), probably due to our early care classification. Treated children are more likely to have been born with birth weight below $1,500 \mathrm{~g}$ ( $5.5 \%$ vs. $7.1 \%)$. Treated children are less likely to have immigrant parents than control children (19\% vs. $21 \%)$.

Figure 1: Child Development and Age
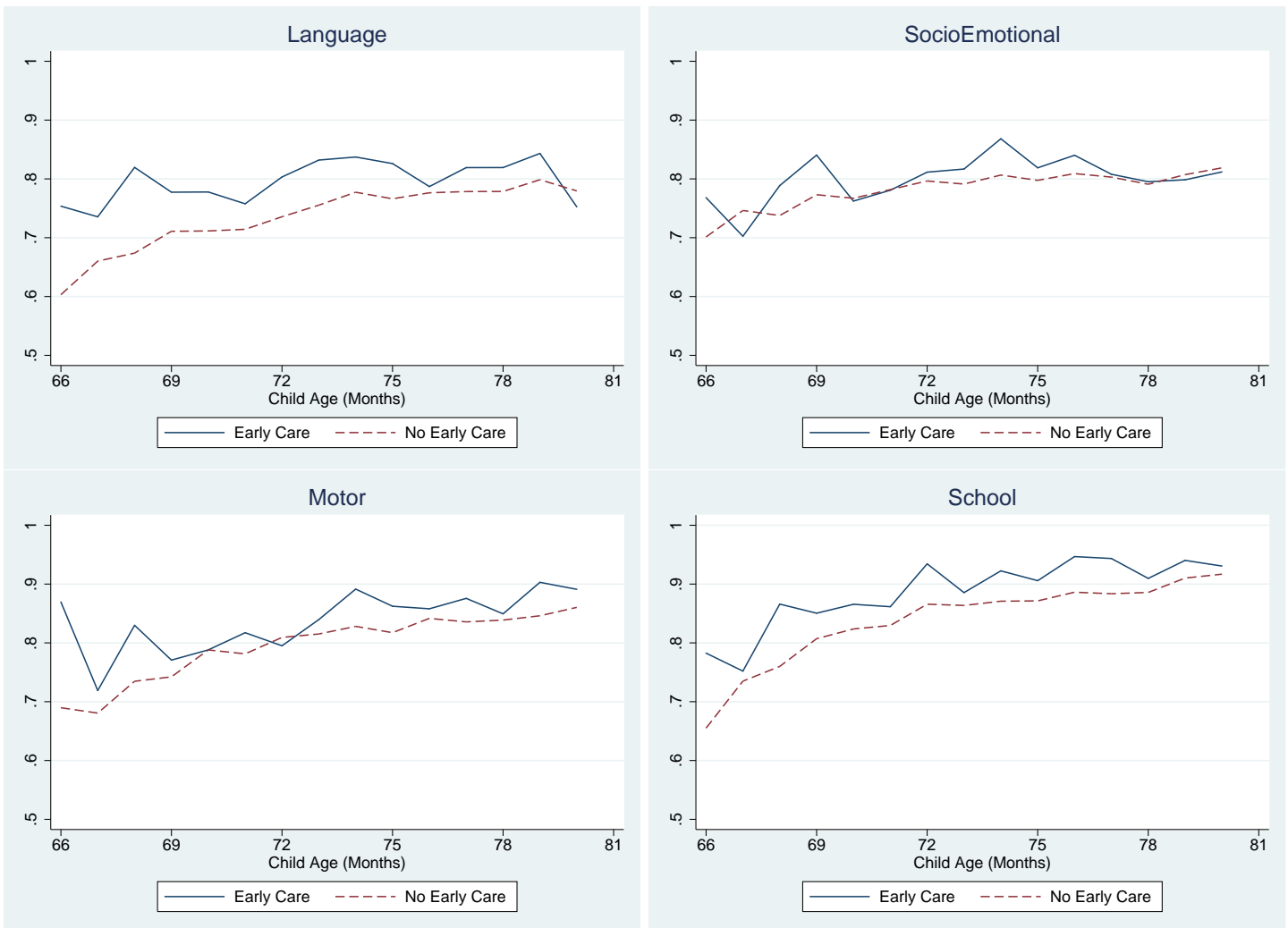

Notes: The Figure reports the fraction of children with no developmental problems as a function of age at interview, separated by early child care attendance status. "Language" refers to a language skills assessment, "SocioEmotional" is an assessment of socio-emotional maturity, "Motor" is a motor skills assessment, and "School" is an assessment of whether the child is ready to enter primary school or not.

Source: school entrance examination, Schleswig-Holstein 2009-2011, our calculations.

Panel C in Table 1 provides information on the characteristics of the mother and family size. About $15 \%$ of treated children and $13 \%$ of control children live with a single parent (in most cases the mother). Thirty-eight percent of treated children but only $28 \%$ of control children are 
Table 1: Descriptive Statistics on Key Variables

\begin{tabular}{lccccc}
\hline \hline & All & Early Care & No Early Care & Diff & z-Ratio \\
\hline & & & & & \\
A. Developmental Outcomes & & & & & \\
Language Skills (D) & 0.753 & 0.790 & 0.749 & 0.041 & $(4.520)$ \\
Socio-Emotional Maturity (D) & 0.791 & 0.796 & 0.790 & 0.006 & $(0.691)$ \\
Motor Skills (D) & 0.810 & 0.824 & 0.809 & 0.015 & $(1.836)$ \\
School Readiness (D) & 0.859 & 0.885 & 0.856 & 0.029 & $(4.214)$ \\
& & & & & \\
B. Child's Characteristics & & & & & \\
Child Age (Months) & 73.854 & 72.686 & 73.960 & -1.274 & $(-10.130)$ \\
Boy (D) & 0.521 & 0.523 & 0.521 & 0.002 & $(0.216)$ \\
Low Birth Weight (D) & 0.069 & 0.055 & 0.071 & -0.016 & $(-3.509)$ \\
Foreign (D) & 0.207 & 0.186 & 0.209 & -0.022 & $(-2.047)$ \\
& & & & & \\
C. Mom's Characteristics & & & & & \\
Mother is Single (D) & 0.132 & 0.154 & 0.130 & 0.024 & $(2.986)$ \\
Mother Has Tertiary Education (D) & 0.303 & 0.380 & 0.295 & 0.085 & $(6.936)$ \\
Mother Education Missing (D) & 0.164 & 0.154 & 0.165 & -0.011 & $(-1.016)$ \\
Number of Siblings & 1.180 & 0.976 & 1.199 & -0.222 & $(-10.945)$ \\
& & & & & \\
D. Care Centers' Characteristics & & & & & \\
Group Size (Children) & 10.240 & 10.436 & 10.223 & 0.213 & $(2.198)$ \\
Staff Age (Years) & 40.623 & 40.692 & 40.616 & 0.076 & $(1.754)$ \\
Staff With Degree (\%) & 62.474 & 62.920 & 62.433 & 0.487 & $(2.408)$ \\
Full-Time Staff (\%) & 27.662 & 27.561 & 27.672 & -0.111 & $(-.340)$ \\
Full-Time Children (\%) & 42.292 & 42.595 & 42.265 & 0.330 & $(0.449)$ \\
\hline & & & & & \\
Children & 36381 & 3047 & 33334 & & \\
\hline \hline
\end{tabular}

Notes: This table reports child, family, and care center background characteristics. The "All" column is the sample average, the "Early Care" column refers to children with early center-based care exposure, and the "No Early Care" column refers to children with no early center-based care exposure. "Diff" calculates the difference between the "Early Care" and "No Early Care" columns, and the "z-Ratio" column provides the asymptotic z-statistic for a test of no difference between the two columns adjusted for clustering at the school district level. Source: school entrance examination, Schleswig-Holstein 2009-2011, our calculations. 
Table 2: Child Care and Child Development: OLS Estimates

\begin{tabular}{lcccc}
\hline \hline & Language & SocioEmotional & Motor & School \\
\hline & & & & \\
Early Care (D) & $0.014^{*}$ & -0.001 & $0.023^{* * *}$ & $0.022^{* * *}$ \\
& $(0.008)$ & $(0.008)$ & $(0.007)$ & $(0.006)$ \\
& & & & \\
\hline Adjusted R2 & 0.098 & 0.087 & 0.104 & 0.113 \\
Children & 36381 & 36381 & 36381 & 36381 \\
\hline \hline
\end{tabular}

Notes: All estimates are based on OLS estimations controlling for the full set of individual characteristics, care center characteristics, regional proxies of child care demand, and school district characteristics as well as for a set of cohort and school district dummies. Inference is based on standard errors that allow for clustering at the school district level.

Source: school entrance examination, Schleswig-Holstein 2009-2011, our calculations

raised by a mother with tertiary education. Treated children have 1 sibling on average, whereas control children have 1.2 siblings on average.

Panel D in Table 1 presents indicators of the quality of care provided by centers. Playgroups consist of about 10 children, caregivers are slightly over 40 years old, and almost two thirds of caregivers have degrees in early childhood education. Fewer than 1 in 4 caregivers work full time, and slightly more than 4 in 10 children are in the center full time. Centers available to treated children have somewhat larger playgroups and employ slightly better trained staff than centers available to control children, but these differences are quantitatively negligible.

Panels B and C in Table 1 reveal several differences between treated children and control children. As a result, the simple comparison of means of children's development in Panel A of Table 1 is biased. Figure 1 adjusts for age at interview but not for other aspects. Table 2 provides ordinary least squares (OLS) estimates of the effect of early child care on child development, adjusting for characteristics of child, mother, and center. Estimates also account for regional measures that function as proxies for the demand for child care, school district features, and the full set of cohort and school district fixed effects. Results indicate that more children with center-based care exposure pass the SEE without a medical diagnosis than children in the control group. Treated children have an advantage on the order of 1.4 percentage points (ppts) in the language dimension, $2.3 \mathrm{ppts}$ in the motor skill dimension, and $2.2 \mathrm{ppts}$ in the school readiness recommendation compared to control children. There are no significant differences in socio-emotional maturity. OLS estimates are somewhat weaker than the simple treated control children comparisons in Panel A of Table 1. This difference hints at selection into early care which is likely based on observables and on unobservables. 


\section{Empirical Framework}

This section presents our framework for estimating marginal treatment effects (MTEs) of centerbased care exposure on child development. The section also discusses the key identifying assumption and estimation of MTE.

\subsection{Setting the Stage}

Let $D=1$ if the child was exposed to early center-based care, and $D=0$ otherwise. $Y_{1}^{s}$ is the potential child development outcome $s$ if the child is treated, and $Y_{0}^{s}$ is the potential child development outcome for the same child if he or she is not treated. The superscript $s$ indexes language and motor skills, socio-emotional maturity, and school readiness.

We adopt the following specifications for the potential outcomes:

$$
\begin{aligned}
Y_{1}^{s} & =X \beta_{1}^{s}+Q \gamma_{1}^{s}+W \eta^{s}+U_{1}^{s} \\
Y_{0}^{s} & =X \beta_{0}^{s}+Q \gamma_{0}^{s}+W \eta^{s}+U_{0}^{s} \\
Y_{1}^{s}-Y_{0}^{s} & =X\left(\beta_{1}^{s}-\beta_{0}^{s}\right)+Q\left(\gamma_{1}^{s}-\gamma_{0}^{s}\right)+U_{1}^{s}-U_{0}^{s}
\end{aligned}
$$

where $X$ is a row vector of child and family characteristics, $Q$ is a row vector of care center quality characteristics, and $W$ is a row vector of of county and school district characteristics along with a full set of cohort and school district dummies.

We expect that the effects of early care on child development outcomes will depend on the quality of care provided by centers and by families. This is why the treatment effect (3) depends on family characteristics, $X$, and center quality features, $Q$. The treatment effect also varies with the unobserved components of the development outcomes, $U_{1}^{s}-U_{0}^{s}$. The treatment effect does not vary with respect to regional features, $W$, because we assume that any differences in the effects of center-based care attendance across school districts or counties operate through regulations on the early child care system and thus through differences in care center quality.

We adopt the following model for the selection into early center-based care:

$$
D=\mathcal{I}\left(X \pi_{X}+Q \pi_{Q}+W \pi_{W}+Z \pi_{Z}-V>0\right)
$$

where $\mathcal{I}(A)$ is the indicator function that takes the value 1 if condition $A$ is true, and zero otherwise. The selection process depends on the same set of observable characteristics as the child development assessments: individual and family background characteristics, $X$; care center quality features, $Q$; and regional features, $W$. Selection into early care also depends on one unobserved determinant, $V$, possibly correlated with the unobserved component of the treatment effect. Additionally, equation (4) contains the variable $Z$ that we intentionally excluded from 
the model of potential outcomes. We discuss below why this exclusion restriction is valid.

We calculate the probability of attending early care, or the propensity score $P(Z)$, as follows: ${ }^{13}$

$$
\begin{aligned}
P(Z) \equiv \operatorname{Pr}(D=1 \mid X, Q, W, Z) & =\operatorname{Pr}\left(X \pi_{X}+Q \pi_{Q}+W \pi_{W}+Z \pi_{Z}-V>0\right) \\
& =\operatorname{Pr}\left(F_{V}\left(X \pi_{X}+Q \pi_{Q}+W \pi_{W}+Z \pi_{Z}\right)>U_{D}\right) \\
& =F_{V}\left(X \pi_{X}+Q \pi_{Q}+W \pi_{W}+Z \pi_{Z}\right)
\end{aligned}
$$

where $F_{V}(\cdot)$ is the cumulative density of the unobserved characteristic $V$, and $U_{D} \equiv F_{V}(V)$ represents different quantiles of $V$ and is uniformly distributed by construction.

Children with larger $U_{D}$ are less likely to enter a care center ceteris paribus. $U_{D}$ measures unobserved costs of or preference for early care attendance. In our setting, $U_{D}$ probably reflects parents' preference for and/or need to rely on center-based care. $U_{D}$ is unlikely to capture center features such as fees or quality, since we condition on quality and identify within school districts, where fee changes are rare over the short time horizon of 3 years that we consider.

The MTE measures how attending early care affects child development for children whose unobserved determinant of attending care is the same as their propensity score. This is a marginal effect in the sense that the parents of these children are indifferent between attending early care or not doing so. The MTE for children with unobserved $U_{D}$ equal to the propensity score is

$$
\begin{aligned}
E\left(Y_{1}^{s}-Y_{0}^{s} \mid X, Q, W, U_{D}=P(Z)\right) & =X\left(\beta_{1}^{s}-\beta_{0}^{s}\right)+Q\left(\gamma_{1}^{s}-\gamma_{0}^{s}\right) \\
& +E\left(U_{1}^{s}-U_{0}^{s} \mid X, Q, W, U_{D}=P(Z)\right)
\end{aligned}
$$

\subsection{Identification}

The key identifying assumption is that $Z$ is independent from the unobserved components of the potential outcomes and the selection equation

$$
Z \mid X, Q, W \Perp U_{1}^{s}, U_{0}^{s}, U_{D}
$$

The ideal instrument, $Z$, tracks exogenous supply shocks within school districts. We use average early care attendance in a school district and school entry cohort as a proxy for the supply of early care in our empirical analysis. Actual early care attendance tracks supply in a situation with excess demand, since all places that are offered on the market are immediately filled. As discussed in detail in Section 2, Schleswig-Holstein has excess demand for places in early care.

\footnotetext{
${ }^{13}$ This is not the same propensity score as in a matching type analysis because it includes an instrumental variable. We index the propensity score only by $Z$, since $Z$ is the key source of variation.
} 
We now provide some descriptive background for this attendance rate. Figure 2 displays the p.d.f. of the average attendance rates across districts for the three school entrance cohorts. Every year, more children attended early center-based care: $5.5 \%$ of the 2009 school entrance cohort attended early center-based care, as did $7.5 \%$ of the 2010 school entrance cohort and $12.5 \%$ of the 2011 school entrance cohort.

Figure 3 discusses the extent to which early care attendance varies within and between school districts. The figure reports the overall average attendance rate (net of the cohort trend), the average attendance rate within school districts, and the average attendance rate within school districts while conditioning on the full set of controls. Results show that the variance in the average attendance rate within school districts is somewhat smaller than the overall variation. However, the support of the average attendance rate within districts remains large. Moreover, adding the set of control variables does not reduce the within-school district variation by much.

Figure 2: Expansions in Early Care Attendance

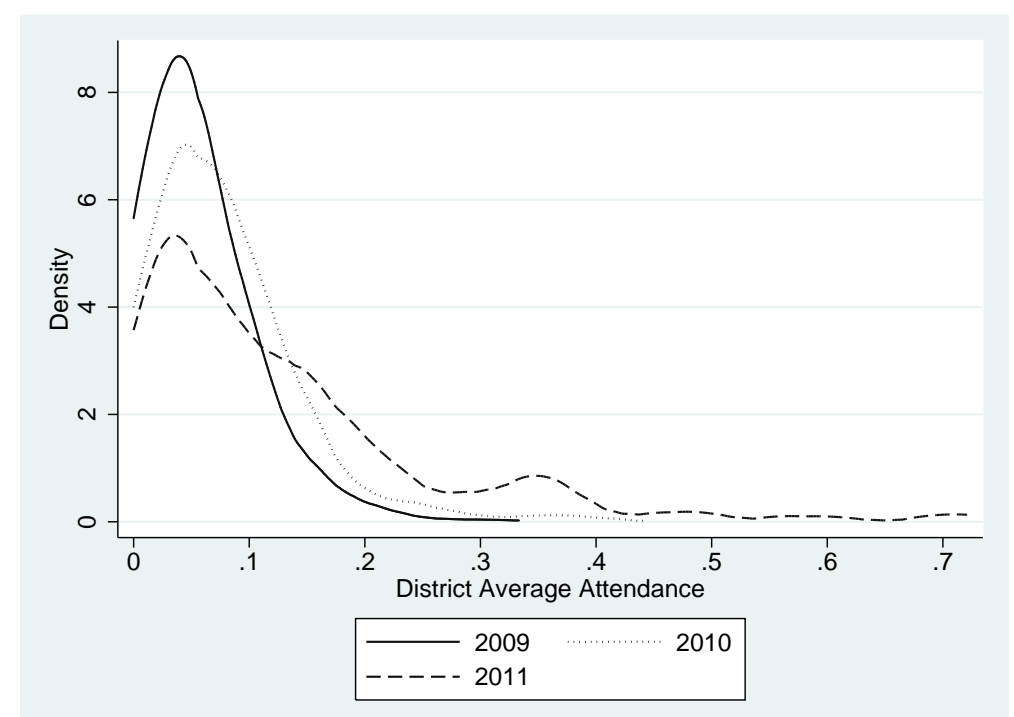

Notes: This graph plots the p.d.f. of the average attendance rate across the three school entrance cohorts. The mean average attendance rate is $5.5 \%$ for the 2009 school-entrance cohort, $7.5 \%$ for the 2010 school-entrance cohort, and $12.5 \%$ for the 2011 school entrance cohort.

Source: school entrance examination, Schleswig-Holstein 2009-2011, our calculations

What are the determinants of the average attendance rate? Table 3 shows that the 2005 reform increased early care attendance substantially. Recall that the 2009 cohort (born in 20022003) attended early care before the 2005 expansion of early care, whereas the 2010 and 2011 cohorts (born in 2003-2005) attended early care after it. In line with this, results show that the 2010 cohort and the 2011 cohort were more likely to attend early care than the 2009 cohort.

Yet Table 3 also shows that expansions in early care were not exogenous, either across counties or across school districts. In line with the allocation of federal funds, expansions were strongest in counties with high female employment (Panel A). Moreover, school districts with 
Figure 3: Variation in the Average Attendance Rate $(Z)$

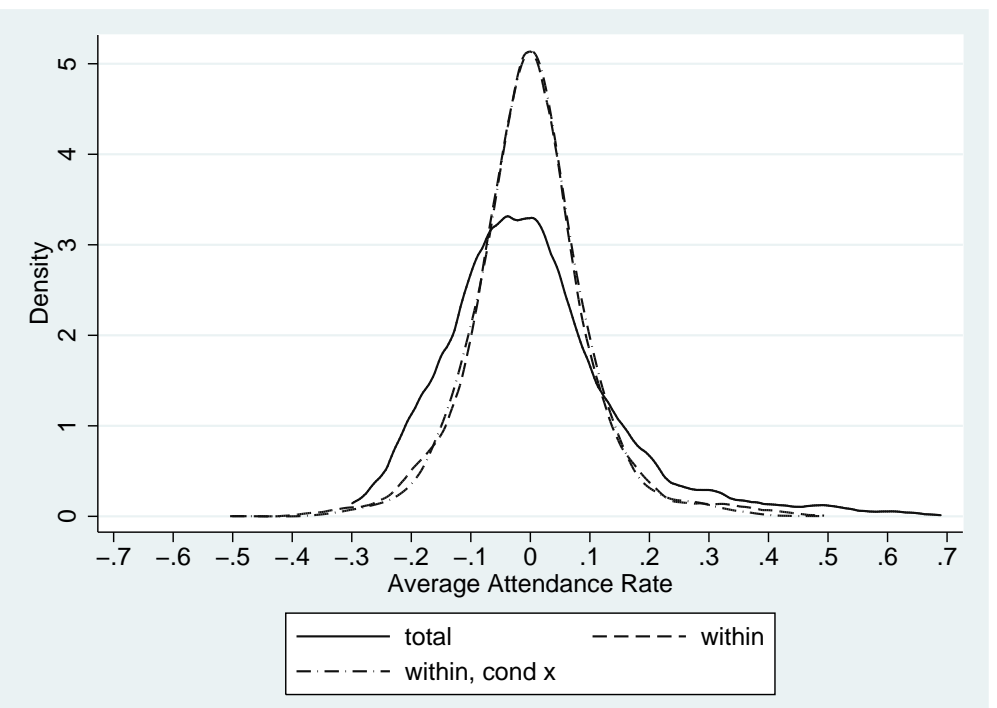

Notes: This graph plots the p.d.f. of the average attendance rate $(Z)$ overall (net of cohort effects), within school districts, and within school districts conditional on $X$. The standard deviation of residual school attendance rates is 0.15 overall, 0.10 within school districts, and 0.09 within school districts and conditional on $X$.

Source: school entrance examination, Schleswig-Holstein 2009-2011, our calculations

a strong need for additional child care places managed to get them (Panel B). In particular, school districts with a larger share of educated mothers or immigrant parents but with smaller families and smaller cohorts experienced the strongest expansion. In addition, expansions were likely to occur at the cost of care quality. Expanding counties offered larger playgroups, and fewer children were attending early care on a full-time basis (Panel C).

Thus, two questions are central from an identification point of view. First, are expansions in the average attendance rate exogenous within school districts? Results in Column 2 of Table 3 test exactly this assumption. These results condition on a full set of school district fixed effects and ask whether average attendance remains correlated with school district variables. The within-school district analysis shows that the average attendance rate is uncorrelated with the characteristics of the school district: the p-value of the test for joint significance of the school district features is 0.701. Importantly, the decrease in significance is mainly due to a decrease in the magnitude of the coefficients relating to proxies for the socio-economic composition of the school districts and not due to an inflation of the respective standard errors. County-level characteristics, however, remain significant predictors of early care attendance. This is expected, as federal funds are allocated across counties according to an annual prediction of demand, which is based on exactly the socio-economic features included in our regression. We therefore keep this set of socio-economic features at the county level as controls in our estimations.

The average attendance rate is conditionally uncorrelated with the socio-economic composition of the school district and thus likely to be unconfounded with any further determinants 
Table 3: Predictors of the Average Center-Based Care Attendance Rate

\begin{tabular}{|c|c|c|}
\hline & $(1)$ & $(2)$ \\
\hline Cohort 2010 (D) & $\begin{array}{c}0.025^{* * *} \\
(0.005)\end{array}$ & $\begin{array}{c}0.018^{* * *} \\
(0.005)\end{array}$ \\
\hline Cohort 2011 (D) & $\begin{array}{c}0.141^{* * *} \\
(0.029)\end{array}$ & $\begin{array}{c}0.137^{* * *} \\
(0.027)\end{array}$ \\
\hline A. Predictors of Demand (County) & & \\
\hline GDP per Capita & $\begin{array}{c}0.003 \\
(0.003)\end{array}$ & $\begin{array}{c}-0.001 \\
(0.003)\end{array}$ \\
\hline Female Employment Rate (\%) & $\begin{array}{c}0.015^{* * *} \\
(0.004)\end{array}$ & $\begin{array}{c}0.009^{* * *} \\
(0.003)\end{array}$ \\
\hline Unemployment Rate (\%) & $\begin{array}{l}-0.000 \\
(0.000)\end{array}$ & $\begin{array}{l}-0.000 \\
(0.000)\end{array}$ \\
\hline Log Children in County 0-2 Years & $\begin{array}{c}0.012 \\
(0.088)\end{array}$ & $\begin{array}{l}-0.041 \\
(0.084)\end{array}$ \\
\hline Migration Rate (\%) & $\begin{array}{c}0.000 \\
(0.001)\end{array}$ & $\begin{array}{l}-0.000 \\
(0.001)\end{array}$ \\
\hline B. Regional Features (School District) & & \\
\hline Log Children in School District Cohort & $\begin{array}{c}-0.012^{* *} \\
(0.005)\end{array}$ & $\begin{array}{c}0.017 \\
(0.015)\end{array}$ \\
\hline Boys (Fract) & $\begin{array}{l}-0.008 \\
(0.035)\end{array}$ & $\begin{array}{c}-0.003 \\
(0.038)\end{array}$ \\
\hline Low Birth Weight (Fract) & $\begin{array}{l}-0.075 \\
(0.052)\end{array}$ & $\begin{array}{l}-0.080 \\
(0.064)\end{array}$ \\
\hline Foreign (Fract) & $\begin{array}{c}0.057^{*} \\
(0.029)\end{array}$ & $\begin{array}{c}-0.003 \\
(0.063)\end{array}$ \\
\hline Number of Siblings (Avg) & $\begin{array}{c}-0.053^{* * *} \\
(0.012)\end{array}$ & $\begin{array}{c}0.012 \\
(0.014)\end{array}$ \\
\hline Single Mothers (Fract) & $\begin{array}{c}0.036 \\
(0.039)\end{array}$ & $\begin{array}{c}0.065 \\
(0.050)\end{array}$ \\
\hline Mother Has Tertiary Education (Fract) & $\begin{array}{c}0.081^{* * *} \\
(0.028)\end{array}$ & $\begin{array}{c}0.015 \\
(0.044)\end{array}$ \\
\hline C. Care Center Quality (County) & & \\
\hline Group Size (Children) & $\begin{array}{c}0.022^{* * *} \\
(0.004)\end{array}$ & $\begin{array}{c}0.020^{* * *} * \\
(0.004)\end{array}$ \\
\hline Staff Age (Years) & $\begin{array}{l}-0.039 \\
(0.031)\end{array}$ & $\begin{array}{l}-0.040 \\
(0.032)\end{array}$ \\
\hline Staff With Degree (\%) & $\begin{array}{c}0.001 \\
(0.005)\end{array}$ & $\begin{array}{l}-0.000 \\
(0.005)\end{array}$ \\
\hline Full-Time Staff (\%) & $\begin{array}{c}0.008 \\
(0.005)\end{array}$ & $\begin{array}{l}0.010^{*} \\
(0.006)\end{array}$ \\
\hline Full-Time Children (\%) & $\begin{array}{c}-0.003^{* * *} \\
(0.001) \\
\end{array}$ & $\begin{array}{c}-0.003^{* * *} \\
(0.001)\end{array}$ \\
\hline County FE & Yes & No \\
\hline District FE & No & Yes \\
\hline County Characteristics (p-Value) & 0.001 & 0.031 \\
\hline District Characteristics (p-Value) & 0.000 & 0.701 \\
\hline Center Characteristics (p-Value) & 0.000 & 0.000 \\
\hline Adj. R2 & 0.287 & 0.586 \\
\hline Children & 36381 & 36381 \\
\hline
\end{tabular}

Notes: This table shows the estimates based on an OLS model where the dependent variable is the level of the average attendance rate. Additional control variables are the set of individual control variables and a set of county dummies in column 1 or a full set of school district dummies in column 2. Standard errors are clustered at the school district level and are shown in parenthesis: ${ }^{*} \mathrm{p}<0.10,{ }^{* *} \mathrm{p}<0.05,{ }^{* * *} \mathrm{p}<0.010$.

Source: school entrance examination, Schleswig-Holstein 2009-2011, our calculations 
of children's development. In other words, conditionally on a full set of school district dummies and our set of controls, the average attendance rate constitutes a valid instrument for individual child care attendance. The only remaining threat to our identification strategy is thus any time-varying confounding variable which is orthogonal to the observable characteristics of the school districts we already control for.

Second, does the composition of a child's peers in early care change when access to early care is expanded? Figure 4 reports how peer composition within school districts changes as a function of average attendance. Peer characteristics hardly change when the number of available slots in center-based care increases, with the exception of children with siblings in expanding school districts. Changing peer composition is thus unlikely to explain heterogeneity in the effects of center-based care when supply increases.

Figure 4: Composition of Peers in Child Care vs. School District Attendance
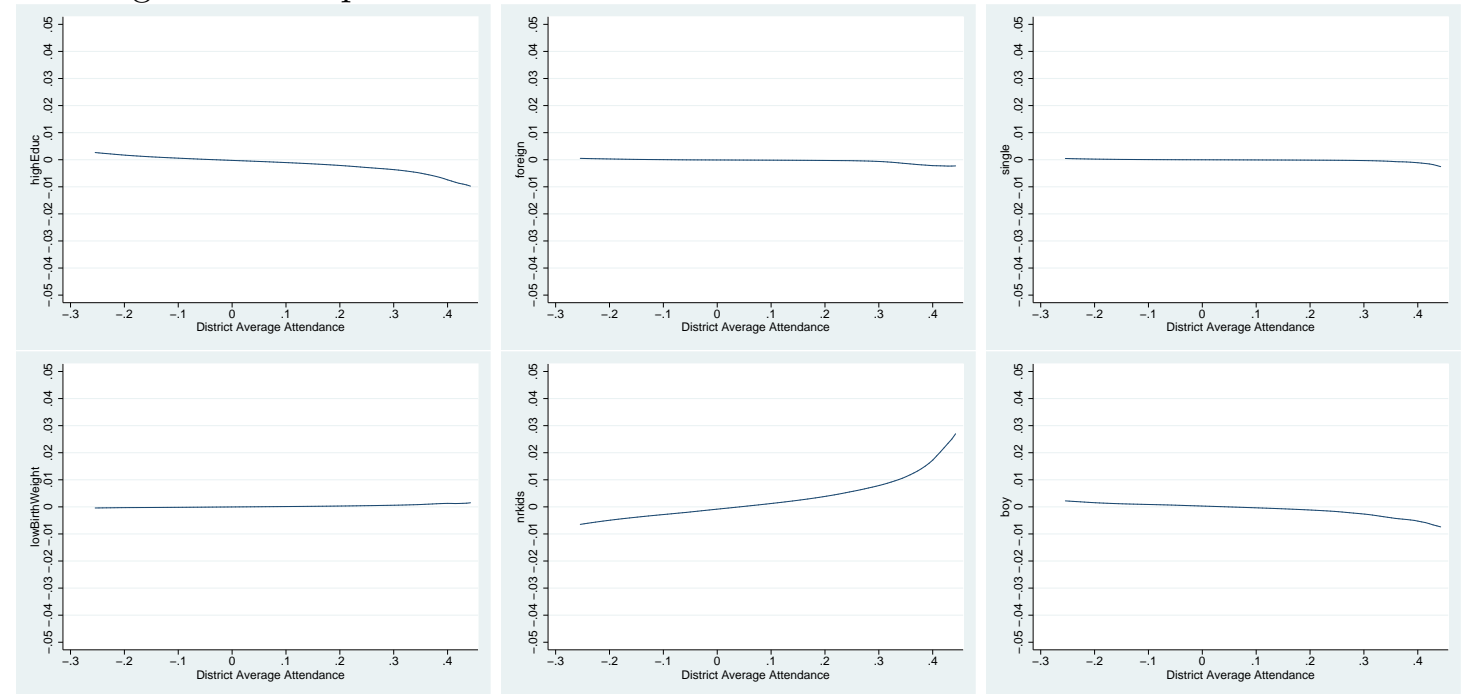

Notes: Epanechnikov Kernel regression with 0.5 bandwidth. Both peer characteristics and school district attendance are expressed as deviations from school district means.

Source: school entrance examination, Schleswig-Holstein 2009-2011, our calculations

Earlier work on MTEs has pioneered this identification strategy. Doyle (2007) uses judges' foster care award propensity as an instrument for whether the individual child is actually placed in foster care. Maestas et al. (2013) and French and Song (2014) use judges' disability award propensity to instrument whether an individual applicant received disability payments or not. The "judge's design" works because a judge's propensity to rule for foster care or disability is unrelated to a child's propensity to commit a crime as an adult in the foster care context or the state of the labor market in the disability context. In a similar vein, our design works because a school district's supply of early care places is unrelated to demand for early care in the short run.

We use the conditional independence assumption (7) to see how child development outcome 
varies with the propensity score, conditional on $X, Q$, and $W$. This so-called reduced form equation is as follows:

$$
\begin{aligned}
E\left(Y^{s} \mid X, Q, W, P(Z)=P\right) & =X \beta_{0}^{s}+Q \gamma_{0}^{s}+W \eta^{s}+P X\left[\beta_{1}^{s}-\beta_{0}^{s}\right]+P Q\left[\gamma_{1}^{s}-\gamma_{0}^{s}\right] \\
& +E\left(U_{0}^{s}+D\left(U_{1}^{s}-U_{0}^{s}\right) \mid X, Q, W, P(Z)=P\right) \\
& =X \beta_{0}^{s}+Q \gamma_{0}^{s}+W \eta^{s} \\
& +P X\left[\beta_{1}^{s}-\beta_{0}^{s}\right]+P Q\left[\gamma_{1}^{s}-\gamma_{0}^{s}\right]+K_{X, Q, W}^{s}(P)
\end{aligned}
$$

We make use of the identifying assumption in two ways. First, conditional independence of $U_{0}^{s}$ from $Z$ implies that $E\left(U_{0}^{s} \mid X, Q, W, P(Z)=P\right)=0$, so the instrument $Z$ can be excluded from the potential outcome without treatment. Conditional independence of $\left(U_{1}^{s}, U_{0}^{s}, U_{D}\right)$ from $Z$ also implies that $E\left(D\left(U_{1}^{s}-U_{0}^{s}\right) \mid X, Q, W, P(Z)=P\right)=P E\left(U_{1}^{s}-U_{0}^{s} \mid X, Q, W, P(Z)=P\right) \equiv$ $K_{X, Q, W}^{s}(P) . \quad K_{X, Q, W}^{s}(P)$ is an unknown function that measures how the component of the treatment effect due to unobserved characteristics, $U_{1}^{s}-U_{0}^{s}$, varies with preference for attending early care, $U_{D} \cdot K_{X, Q, W}^{s}(P)$ depends on the propensity score in two ways. First, increasing $P$ means that an increasing proportion of children attend early care, so the reduced form outcome reflects more of the unobserved component of the treatment effect, $E\left(U_{1}^{s}-U_{0}^{s} \mid X, Q, W, P(Z)=\right.$ $P)$. Second, increasing $P$ increases preference against early care, $U_{D}$. This in turn changes the unobserved component of the treatment effect, $E\left(U_{1}^{s}-U_{0}^{s} \mid X, Q, W, P(Z)=P\right)$, if there is a correlation between preference for early care and its effects on child development.

\subsection{Estimation}

The MTE is the partial derivative of the reduced form with respect to the propensity score (Heckman and Vytlacil, 2000):

$$
\begin{aligned}
E\left(Y_{1}^{s}-Y_{0}^{s} \mid X, Q, W, U_{D}=P\right) & =\frac{\partial E\left(Y^{s} \mid X, Q, W, P(Z)=P\right)}{\partial P} \\
& =X\left[\beta_{1}^{s}-\beta_{0}^{s}\right]+Q\left[\gamma_{1}^{s}-\gamma_{0}^{s}\right] \\
& +E\left(U_{1}^{s}-U_{0}^{s} \mid X, Q, W, P(Z)=P\right)
\end{aligned}
$$

We estimate the MTE in three steps. In the first step, we use a probit model to estimate the propensity score. The probit works better than the linear probability model, since the probit produces estimates of the participation probability that are bounded between zero and one. We approximate how the propensity score depends on $Z$ by adopting a third-order polynomial approximation to an unknown function.

In the second step, we estimate models of the outcome equations that include a flexible polynomial of the estimated propensity score $\hat{P}$, aiming to estimate the unknown function 
$K_{X, Q, W}^{s}(P)$. Two considerations are key at this stage. The first consideration is the polynomial order. A first-order polynomial, and thus a linear model, imposes the assumption that the MTE does not change with unobserved determinants of early care attendance. This assumption rules out correlation between preferences for early care attendance and its causal effects. Our baseline specification adopts a third-order polynomial, and our sensitivity analysis uses a fifth-order polynomial. The second consideration is flexibility. Our baseline analysis assumes that $K_{X, Q, W}^{s}(P)$ is the same for all children. We relax this potentially misleading simplification in a sensitivity analysis where $K_{X, Q, W}^{s}(P)$ differs depending on the educational level of the mother and whether the child's parents are immigrants.

In the third step, we calculate the MTE as the partial derivative of the estimated reduced form with respect to the propensity score. We base inference on standard errors that allow for clustering at the level of school districts.

\section{Results}

This section presents estimates of the propensity score, estimates of the MTE of early centerbased care exposure on child development, and policy simulations of expanding early care.

\subsection{Who Is in Center-based Care and Who Isn't?}

We analyze which children attend early care in a probit framework that includes the average school district attendance rate, a full set of child, family, care center, and regional characteristics, and a set of cohort and school district fixed effects. This corresponds to an estimate of equation (5). ${ }^{14}$ Table 4 displays marginal effects for the instrument and all individual and care center characteristics (see Table B.1 in Appendix B for the full set of estimates). Standard errors account for clustering at the school district level (335 cells). ${ }^{15}$

Results indicate that the average attendance rate is a strong predictor of individual attendance. The relationship between individual attendance and the average attendance rate is non-linear, being flat at intermediate attendance rates and increasing strongly at low and high average attendance rates. This functional form mimics the purely descriptive relationship between individual and average attendance (Figure B.1 in the Appendix B).

Which characteristics predict individual care center attendance? Children who are older at the date of the SEE are less likely to have attended early center-based care, probably a result

\footnotetext{
${ }^{14}$ Explaining individual attendance by average attendance may be affected by the "reflection problem," a mechanical positive correlation between individual attendance and school district mean attendance (Manski, 1993). However, this problem becomes less significant once background characteristics are added. We have assessed sensitivity of our estimates to excluding the child we analyze when calculating the average attendance rate, a specification that does not suffer from the reflection problem. Results are available upon request from the authors.

${ }^{15}$ We also explored clustering at the county-year level, the level at which predictors of early care demand and care center quality are measured. We obtained standard errors that are similar to the ones we report.
} 
Table 4: Determinants of Children's Early Care Attendance

\begin{tabular}{lc}
\hline \hline District Attendance (Z) & $1.479^{* * *}$ \\
& $(0.067)$ \\
Z pw 2 & $-3.495^{* * *}$ \\
& $(0.351)$ \\
Z pw 3 & $3.012^{* * *}$ \\
& $(0.446)$ \\
Cohort 2010 (D) & -0.000 \\
& $(0.003)$ \\
Cohort 2011 (D) & 0.014 \\
& $(0.011)$ \\
Child Age (Months) & $-0.004^{* * *}$ \\
& $(0.000)$ \\
Boy (D) & 0.001 \\
& $(0.002)$ \\
Low Birth Weight (D) & $-0.014^{* * *}$ \\
& $(0.004)$ \\
Foreign (D) & $-0.010^{* * *}$ \\
& $(0.003)$ \\
Number of Siblings & $-0.013^{* * *}$ \\
& $(0.001)$ \\
Mother is Single (D) & $0.015^{* * *}$ \\
& $(0.004)$ \\
Mother Has Tertiary Education (D) & $0.021^{* * *}$ \\
& $(0.003)$ \\
\hline District FE & Yes \\
Z terms (Chi2) & 3008.0 \\
Individual Characteristics (p-Value) & 0.000 \\
Center Characteristics (p-Value) & 0.004 \\
County Characteristics (p-Value) & 0.012 \\
District Characteristics (p-Value) & 0.000 \\
Log Likelihood & -8656.5 \\
Children & 36381 \\
\hline \hline
\end{tabular}

Notes: This table shows marginal effects resulting from probit model estimates of the propensity score. Additional control variables are center characteristics and regional proxies of early child care demand, as well as a full set of school district dummies and a constant term. Standard errors are clustered at the school district level and are shown in parenthesis: ${ }^{*} \mathrm{p}<0.10,{ }^{*} \mathrm{p}<0.05$, *** $\mathrm{p}<0.010$.

Source: school entrance examination, Schleswig-Holstein 2009-2011, our calculations 
Figure 5: The Propensity Score for Treated and Control Children

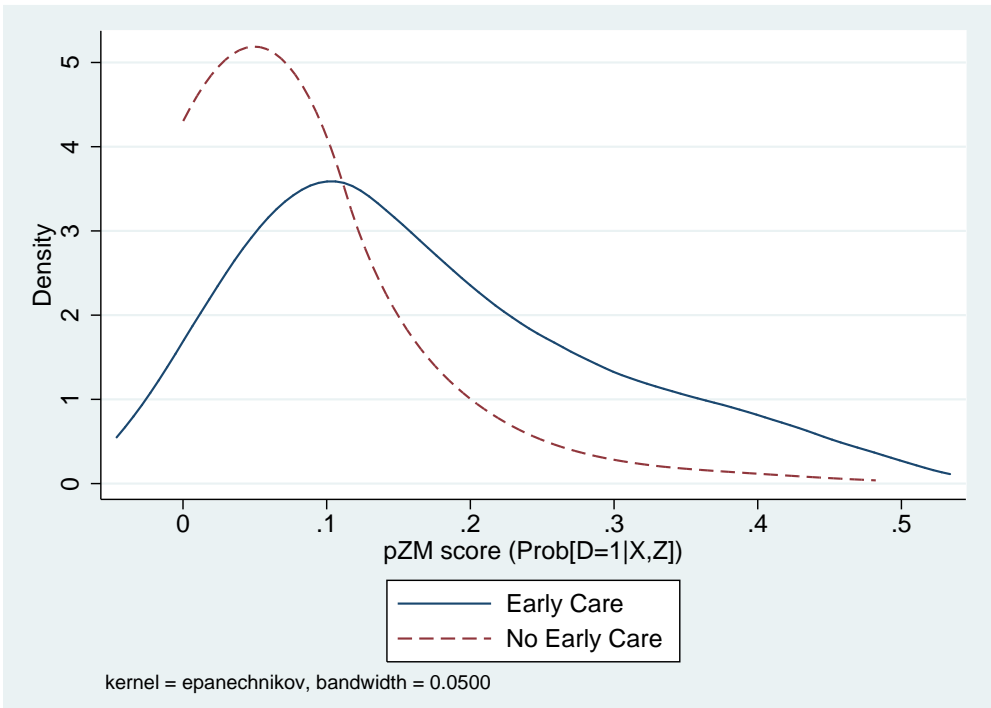

Notes: This graph plots the p.d.f. of the estimated propensity scores separately for children with some exposure to early center-based care and children with no exposure to it. 1123 observations lie outside the common support region.

Source: school entrance examination, Schleswig-Holstein 2009-2011, our calculations

of our early care attendance classification. Boys and girls are equally likely to have attended early care. Children with immigrant parents, low birth weight, or many siblings are less likely to be in center-based care. Children of single mothers are more likely to be in center-based care, probably because they are granted preferential access. Children of highly educated mothers are also substantially more likely to be in center-based care, probably because they are placed first on the waiting list.

The probit results serve to calculate the propensity score. Figure 5 shows the density of the propensity score, separately for treated and control children. The estimated propensity score, ranging from $0 \%$ to about $50 \%$, has limited support. Limited support precludes us from using MTEs to simulate the average effect of attending early care on all children but not from using MTEs to simulate the effects of small to moderate policy expansions. The propensity to attend center-based care is lower for control children than for treated children. But the overlap between the two distributions is substantial. Only $3.1 \%$ of all children have a propensity score that is outside the common support. We keep children outside the common support in our baseline analysis. Results (not shown) are not sensitive to excluding them.

MTEs are estimated by varying the average attendance rate, $Z$, conditional on observed characteristics. This works well if there is variation in the propensity score even if we condition on characteristics. In order to discuss this important issue, we group children into deciles based on their observed characteristics' effect on the propensity score (based on the linear index $\left.X \hat{\pi}_{X}+Q \hat{\pi}_{Q}+W \hat{\pi}_{w}\right)$. Children are very similar with respect to characteristics other than the 
Figure 6: Does Average Attendance Vary in Groups With Similar Observables?

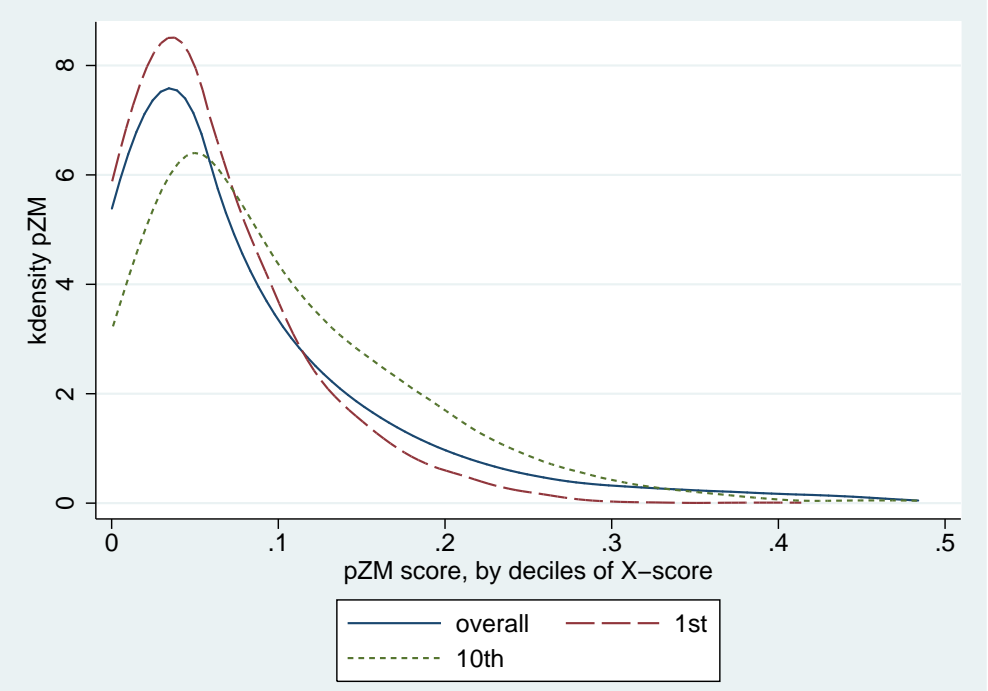

Notes: This graph plots the p.d.f. of the estimated propensity scores, overall, and separately for children with the lowest (1st decile) and highest (10th decile) observed component of the propensity score, i.e., $X \hat{\pi}_{X}+Q \hat{\pi}_{Q}+W \hat{\pi}_{w}$. Results show strong overlap in the support of the propensity score.

Source: school entrance examination, Schleswig-Holstein 2009-2011, our calculations

average attendance rate within a decile. Figure 6 reports the p.d.f. of the propensity score overall and for children with the lowest decile and the highest decile of the index of observed characteristics. Results indicate strong overlap of the support of the lowest and highest decile. The average attendance rate, $Z$, therefore generates strong variation in the propensity score $(P(Z))$, even in groups of children with very similar values of observed characteristics. 


\subsection{How Does Early Care Affect Child Development?}

All MTE estimates are based on the empirical specification (8). We express characteristics as deviations from the sample means, ensuring that the coefficients attached to the propensity score and its higher-order polynomial terms measure the MTE for children with sample average characteristics. All child development measures are binary, taking the value 1 if there is no development problem and 0 otherwise. We adopt linear probability models in all empirical analyses. Standard errors allow for clustering at the school district level. Table B.2 in Appendix B provides the full set of estimates.

Figure 7 shows how the MTEs change with $U_{D}$, the unobserved component of the MTEs probably reflecting parents' preferences for early care. On average, MTEs decrease with unobserved preferences against center-based care attendance. ${ }^{16}$ This pattern is most pronounced for language skills: the return to center-based care for children with the highest chances to attend center-based care amounts to 0.35 ppts; these positive returns slowly fade out and become insignificant for children with lower chances to attend center-based care (i.e., with unobserved heterogeneity above 0.12). The vertical dashed line identifies the MTE for the average child. This "average MTE" amounts to 0.21 and is statistically significant. The pattern is similar for children's motor skills and school readiness but is less pronounced: the effects of center-based care on motor skills and school readiness are positive and significantly different from zero (at a $10 \%$ significance level) for children with the highest chances to attend center-based care $(0.24$ ppts and 0.19 ppts, respectively) and become insignificant for children with lower chances to attend center-based care (with unobserved heterogeneity above 0.15 and 0.14 , respectively). The average MTE is $0.16 \mathrm{ppts}$ for motor skills and $0.13 \mathrm{ppts}$ for school readiness. In contrast, the MTEs for socio-emotional maturity are rather flat and significantly different from zero (at the $5 \%$ significance level) only for children with unobserved heterogeneity between 0.13 and 0.30 . The average MTE is insignificant for socio-emotional maturity. ${ }^{17}$

The pattern of decreasing MTEs suggests that demand for early center-based care is a function of expected returns on early center-based care, or that the choice to use early care is based on expected gains. Parents who expect their child to benefit from attending a care center want to place their child in early center-based care. Selection based on gains was first postulated by Roy (1951). There could be at least three reasons for selection based on gains. First, parents who can provide better care at home will be reluctant to sent their child into early care. Second,

\footnotetext{
${ }^{16}$ This pattern is not a product of our empirical specification. Figure B.2 shows the partial derivative of child development outcomes with respect to the average attendance rate. Child development decreases as the average attendance rate increases. Appendix B, Figure B.3, shows how baseline estimates adopting a third-order polynomial compare to a sensitivity analysis adopting a fifth-order specification. Results indicate that fifth-order MTEs are within the $95 \%$ confidence band of our baseline estimates.

${ }^{17}$ Table B.2 in Appendix B displays the p-values of joint significance tests of the second- to third-order polynomial terms in the propensity score (line "Het . unobs."). A rejection of this test points toward significant heterogeneity in the MTEs with respect to unobserved characteristics. These tests reveal significant heterogeneity in the effects of center-based care exposure only in terms of language skills (at the $10 \%$ significance level).
} 
Figure 7: How Do Marginal Treatment Effects Vary With Unobserved Preferences?

A. Language Skills

Language

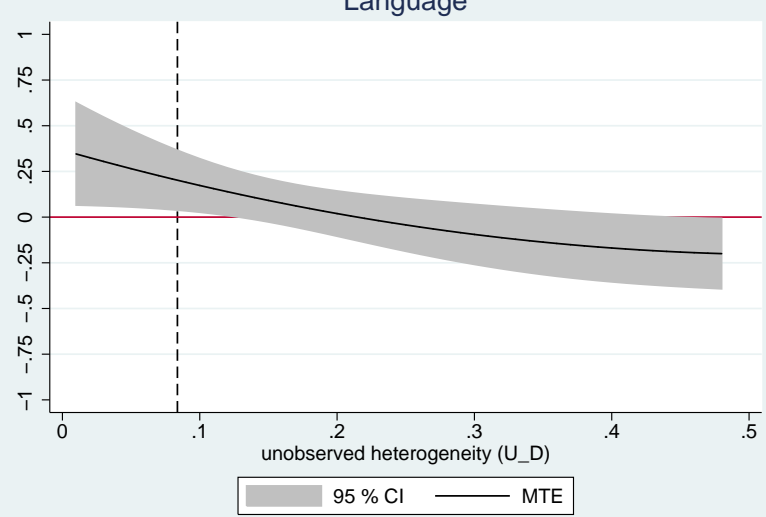

C. Motor Skills

Motor

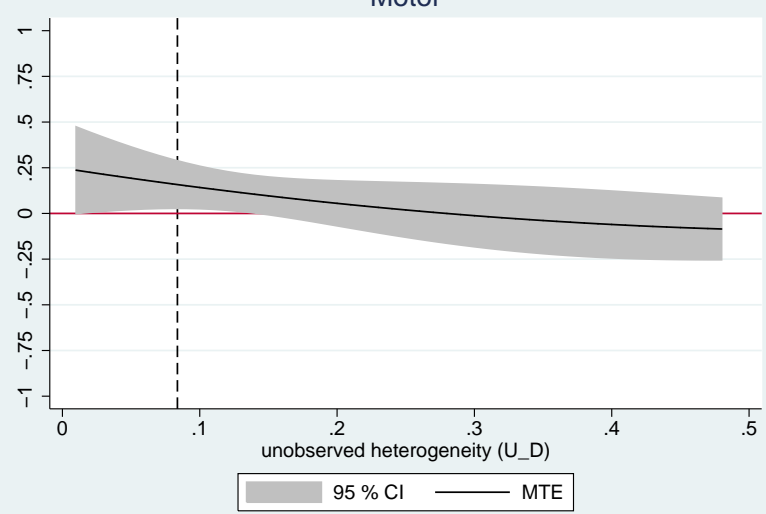

B. Socio-Emotional Maturity

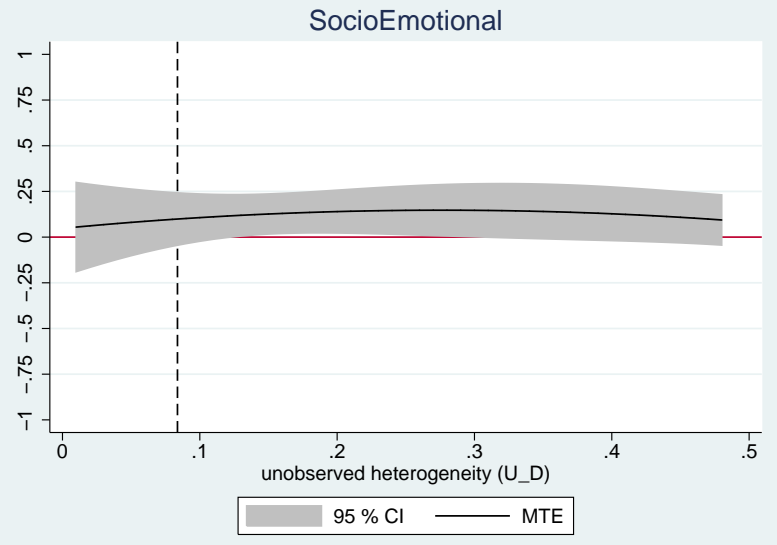

D. School Readiness

School

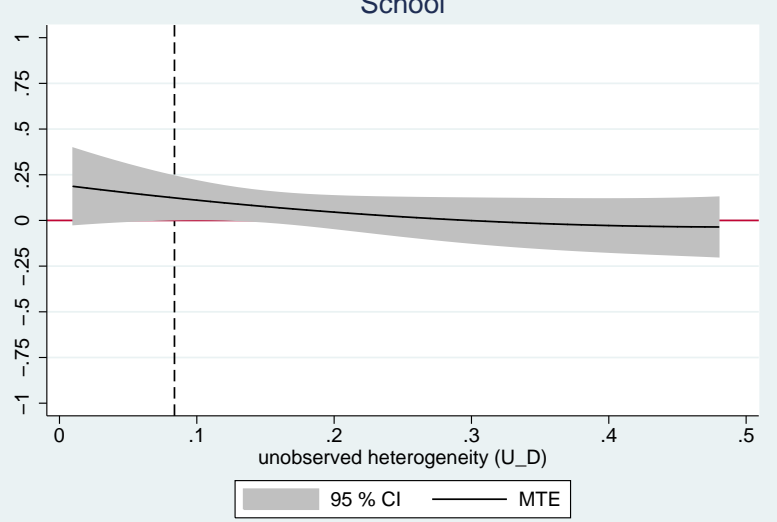

Notes: The graph plots the MTE for the average child as a function of unobserved determinants, $U_{D}$, along with the $95 \%$ confidence interval. Estimates use within-school district variation in the average care center attendance rate as an instrument for individual attendance. The vertical dashed lines indicate the average probability of being in early center-based care. 
children who are less likely to attend center-based care may be in need of more specialized care, for instance, because they suffer from developmental deficits (see, e.g., Drange et al., 2014 or Bucarey et al., 2014). Such specialized care may not be provided by care centers offering care to many children. A third explanation may be peer effects. The environment in the care center may be less stimulating for the development of the child in areas that provide generous access to early care. This story, however, is unlikely to be relevant, as the composition of children attending early care did not change when access to early care was expanded (see Figure 4).

How do the effects of early care vary with child or mother characteristics? Table 5 shows that the effects of early care differ by socio-economic status of the child. Early care is 6.9 ppts more beneficial for developing socio-emotional maturity for children of less educated mothers than for children of highly educated mothers. Children with immigrant parents benefit 9.6 ppts more in school readiness than children with native parents. There are no further significant differences in the effects of early center-based care attendance. ${ }^{18}$

Table 6 discusses whether the effects of early care differ with center quality. Findings indicate that group size, staff age, staff training, and staff work intensity matter for children's development. The effects are sizeable. A child is $7.3 \mathrm{ppts}$ more likely to suffer from motor development problems per additional child in his or her playgroup. A child is 9.7 ppts less likely to have an issue with language development and 12.5 ppts less likely to have an issue with motor skill development per additional year of his or her caregiver's age. A child attending a center with a one ppt higher proportion of trained staff has a 2.2 ppts lower risk of motor skill deficiency. ${ }^{19}$ Finally, a one ppt higher share of full-time working staff leads to improved school readiness by 1.6 ppts. The evidence regarding the intensive margin of care center attendance, however, is not clear-cut: the higher the share of children attending center-based care on a full-time basis, the better the children's language development (a one ppt increase in the share of children attending center-based care on a full-time basis leads to a 0.8 ppts increase in children's language skills). ${ }^{20}$ Yet we also observe a decrease in children's school readiness (a one ppt increase in the share of children attending center-based care on a full-time basis leads to a 0.5 ppts decrease in children's school readiness). ${ }^{21}$

\footnotetext{
${ }^{18}$ Table 5 shows the p-value of a joint test of significance of the parameters capturing heterogeneity of the treatment effect with respect to observed individual characteristics (line "Individual Characteristics (p-value)"). Overall, there is no evidence for significant heterogeneity with respect to observable child or family background characteristics in the returns on center-based care attendance for any child development domain.

${ }^{19}$ Looking at cognitive skills and small class interventions, the US literature has concluded that teacher degrees do not matter (see for instance Krueger and Whitmore (2001)). Our findings for language skills mirror that conclusion. Yet we also find that an early childhood education degree matters for motor skills, a development dimension that has received less attention thus far.

${ }^{20}$ Walters (2014) also finds that the proportion of children in full-time day care predicts better cognitive outcomes in his reanalysis of Head Start.

${ }^{21}$ Table 6 shows the p-value of a joint test of significance of the parameters capturing heterogeneity of the treatment effect with respect to observed characteristics of care center quality ("Center Characteristics (p-value)" row). There is evidence of significant (at the $5 \%$ significance level) heterogeneity in the MTEs in language and motor skills.
} 
Table 5: How Do Marginal Treatment Effects Vary With Child and Mother Characteristics?

\begin{tabular}{lcccc}
\hline \hline & Language & SocioEmotional & Motor & School \\
\hline $\mathrm{pZ} *$ Child Age & -0.007 & 0.011 & 0.007 & -0.007 \\
& $(0.006)$ & $(0.007)$ & $(0.006)$ & $(0.005)$ \\
$\mathrm{pZ} *$ Boy & 0.013 & 0.021 & -0.016 & 0.021 \\
& $(0.042)$ & $(0.039)$ & $(0.048)$ & $(0.034)$ \\
$\mathrm{pZ} *$ Low Birth Weight & -0.024 & -0.099 & -0.085 & -0.123 \\
& $(0.111)$ & $(0.107)$ & $(0.120)$ & $(0.114)$ \\
$\mathrm{pZ} *$ Foreign & -0.002 & -0.035 & -0.042 & $0.096^{* *}$ \\
& $(0.079)$ & $(0.046)$ & $(0.048)$ & $(0.045)$ \\
$\mathrm{pZ}{ }^{*}$ Number of Siblings & -0.016 & 0.029 & 0.041 & 0.011 \\
& $(0.029)$ & $(0.020)$ & $(0.027)$ & $(0.021)$ \\
$\mathrm{pZ} *$ Mother is Single & 0.026 & 0.027 & 0.028 & -0.007 \\
& $(0.068)$ & $(0.069)$ & $(0.066)$ & $(0.054)$ \\
$\mathrm{pZ} *$ Mother has Higher Education & -0.018 & $-0.069 *$ & -0.018 & 0.047 \\
& $(0.043)$ & $(0.038)$ & $(0.043)$ & $(0.037)$ \\
\hline Individual Characteristics (p-value) & 0.951 & 0.369 & 0.631 & 0.214 \\
Center Characteristics (p-value) & 0.048 & 0.437 & 0.029 & 0.143 \\
Unobserved Characteristics (p-value) & 0.076 & 0.111 & 0.100 & 0.230 \\
$\mathrm{R}$-squared & 0.098 & 0.087 & 0.104 & 0.113 \\
Children & 36381 & 36381 & 36381 & 36381 \\
\hline \hline
\end{tabular}

Notes: This table shows reduced-form estimates of all child development assessments projected on the propensity score (third order polynomial), the set of control variables (individual, care center, county, and school district features as well as a set of cohort and school district dummies), and the interactions between the propensity score and all individual and care center features. Each row displays the parameter belonging to the interaction between the propensity score and the respective feature. These parameters allow us to assess for whom child care attendance exhibits greater effects. Standard errors are clustered at the school district level and are shown in parenthesis: $* \mathrm{p}<0.10, * * \mathrm{p}<0.05, * * * \mathrm{p}<0.010$.

Source: school entrance examination, Schleswig-Holstein 2009-2011, our calculations. 
Table 6: How Do Marginal Treatment Effects Vary With Care Center Quality?

\begin{tabular}{lcccc}
\hline \hline & Language & SocioEmotional & Motor & School \\
\hline $\mathrm{pZ} *$ Children in Group & -0.039 & 0.008 & $-0.073^{* * *}$ & -0.003 \\
& $(0.032)$ & $(0.024)$ & $(0.022)$ & $(0.020)$ \\
$\mathrm{pZ} *$ Staff Age (Years) & $0.097^{*}$ & 0.042 & $0.125^{* *}$ & 0.068 \\
& $(0.058)$ & $(0.061)$ & $(0.054)$ & $(0.047)$ \\
$\mathrm{pZ} *$ Trained Staff (\%) & 0.014 & 0.002 & $0.022^{* *}$ & 0.001 \\
& $(0.010)$ & $(0.010)$ & $(0.009)$ & $(0.008)$ \\
$\mathrm{pZ} *$ Staff Full-Time (\%) & 0.000 & 0.003 & 0.007 & $0.016^{* *}$ \\
& $(0.010)$ & $(0.007)$ & $(0.006)$ & $(0.006)$ \\
$\mathrm{pZ} *$ Child Full-Time (\%) & $0.008^{* *}$ & -0.006 & -0.001 & $-0.005^{*}$ \\
& $(0.003)$ & $(0.004)$ & $(0.003)$ & $(0.003)$ \\
\hline Individual Characteristics (p-value) & 0.951 & 0.369 & 0.631 & 0.214 \\
Center Characteristics (p-value) & 0.048 & 0.437 & 0.029 & 0.143 \\
Unobserved Characteristics (p-value) & 0.076 & 0.111 & 0.100 & 0.230 \\
R-squared & 0.098 & 0.087 & 0.104 & 0.113 \\
Children & 36381 & 36381 & 36381 & 36381 \\
\hline \hline
\end{tabular}

Notes: Estimates in this table stem from a reduced-form estimation of all skill dimensions projected on the propensity score (third order polynomial), the set of control variables (individual, care center, county, and school district features as well as a set of cohort and school district dummies) and the interactions between the propensity score and all individual and care center features. Each row displays the parameter belonging to the interaction between the propensity score and the respective feature. These parameters allow us to assess which type of care center leads to greater effects. Standard errors are clustered at the school district level and are shown in parenthesis: ${ }^{*} \mathrm{p}<0.10,{ }^{* *} \mathrm{p}<0.05,{ }^{* * *} \mathrm{p}<0.010$.

Source: school entrance examination, Schleswig-Holstein 2009-2011, our calculations. 
These results indicate that the effects of early care depend substantially on the quality of available care centers. Expansions in coverage often require concessions in care center quality (see Table 3). Analyses that do not take quality features of care centers into account are likely to provide biased estimates of the returns on early care. Indeed, we find that MTE estimates are substantially lower once we omit early care characteristics (Figure B.5 in Appendix B). However, the difference between the two sets of MTEs is not large enough to be statistically significant.

So far, we have assumed that the component of the MTE that captures the unobserved determinant of attending care, parents' preferences, is identical across individuals. We now relax this assumption and provide separate estimates for three groups of children: children of highly educated mothers, children of less educated mothers, and immigrant children. It is useful to probe results in more detail, since the unobserved determinant of center-based care attendance might vary with mother's education and parents' ethnic origin.

Figure 8 shows MTEs by subgroup. MTEs are fairly flat, indicating no significant effect of center-based care attendance for children of highly educated mothers (Panel A). In contrast, MTEs are very large and positive for children of less educated mothers and children of immigrants when parents have a strong preference for them to attend early care (Panels B and C). Yet MTEs again rapidly decrease as preference against attending early center-based care increases.

What explains the absence of any significant returns on early care for children of highly educated mothers? Marginal returns on inputs into children's human capital production function are positive but decrease according to the human capital production theory (Cunha and Heckman, 2007). Hence, if the investments of highly educated parents are already sizable, it may be that any additional investment (such as stimulation experienced in the care center) has no further significant return. One fact that supports this hypothesis is that children of highly educated mothers on average perform better across all development dimensions than children of less educated mothers regardless of center-based care attendance. Hence, it is possible that these children are currently saturated and have nothing to gain but also nothing to loose by attending a care center. These findings are consistent with the view that care offered by centers is a substitute for care offered by mothers, as suggested in research on primary education (e.g., in the literature on project STAR by Krueger and Whitmore (2001) or Chetty et al. (2011) or College Education (Dale and Krueger, 2002).

MTEs clearly differ across subgroups. Does this imply that our baseline estimates are biased? We assess the sensitivity of our baseline results by aggregating the MTEs resulting from the subgroup analysis and compare them to baseline estimates of the MTEs. Results indicate strong agreement between the baseline estimates and the "two-step" estimates from the conditional approach (Figure B.4 in Appendix B). In fact, the two estimates are statistically indistinguishable. We conclude that the key assumption of our baseline analysis that MTEs do not vary with observed characteristics does not bias our conclusions with respect to the average 
Figure 8: Marginal Treatment Effects Across Observable Subgroups

A. Highly Educated
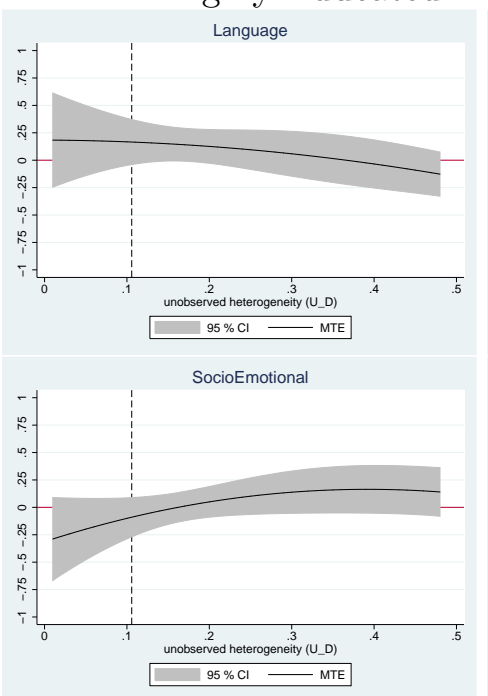

Motor

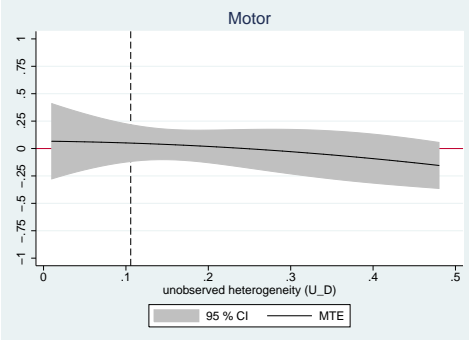

School

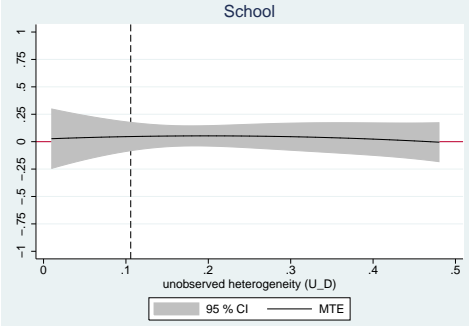

B. Less Educated

Language

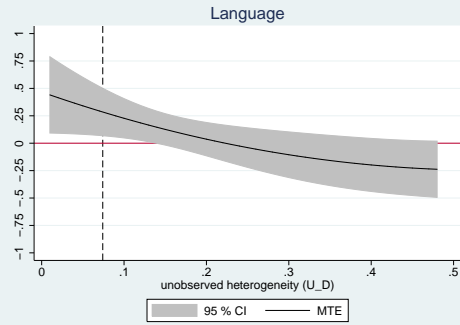

SocioEmotional

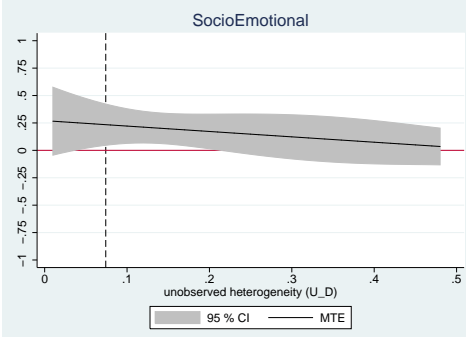

Motor

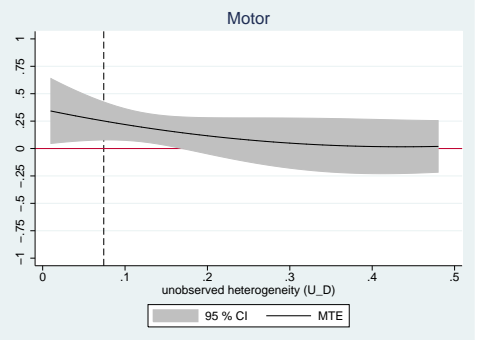

School

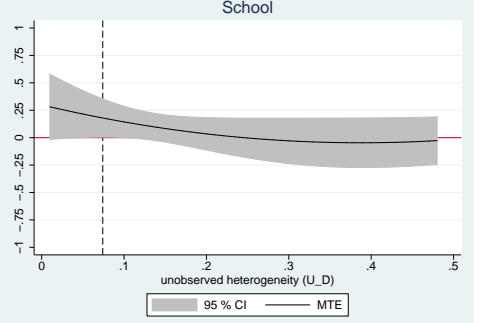

C. Foreign

Language

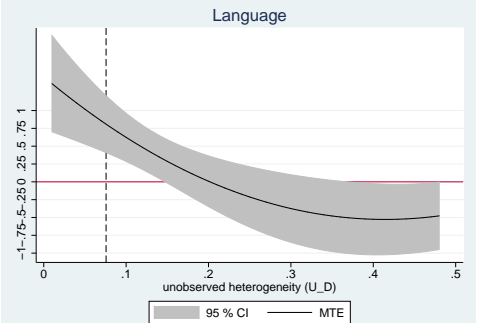

SocioEmotional

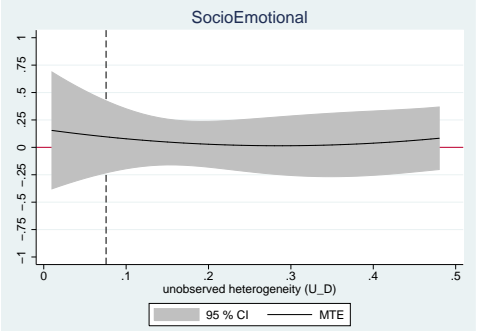

Motor

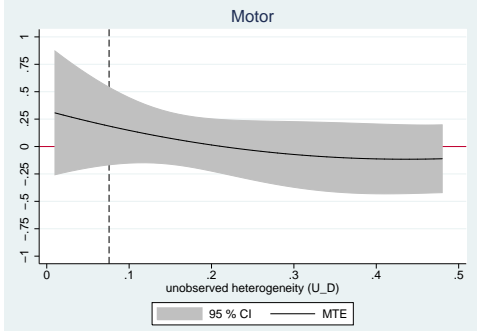

School

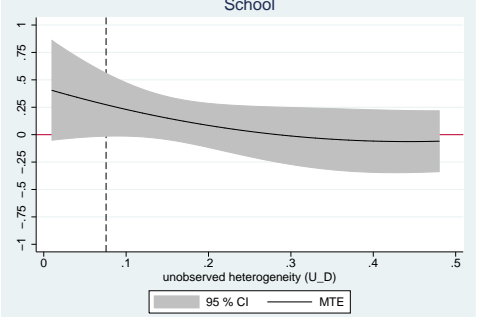

Notes: The graph plots the MTE for the average child in three subgroups - children who have highly educated mothers (column A), children who have less educated mothers (column B), and children who have foreign parents (column C) - as a function of unobserved determinants, $U_{D}$, along with the $95 \%$ confidence interval. Estimates use within-school district variation in the average attendance rate as instruments for individual attendance. The vertical dashed lines indicate the average probability of being in early care. 
Table 7: Simulations of Alternative Early Care Expansion

\begin{tabular}{lcccccccc}
\hline & \multicolumn{2}{c}{ Overall } & \multicolumn{2}{c}{ Highly Educated } & \multicolumn{2}{c}{ Less Educated } & \multicolumn{2}{c}{ Foreign } \\
\hline A. From 0 to 8.4\% & & & & & & & & \\
Language & $.244^{* *}$ & $(.113)$ & .095 & $(.169)$ & $.339^{* *}$ & $(.140)$ & $1.042^{* * *}$ & $(.270)$ \\
SocioEmotional & .041 & $(.097)$ & -.203 & $(.152)$ & $.195^{*}$ & $(.121)$ & .079 & $(.215)$ \\
Motor & $.150^{*}$ & $(.093)$ & .045 & $(.142)$ & $.231^{* *}$ & $(.113)$ & .181 & $(.231)$ \\
School & .115 & $(.083)$ & .013 & $(.112)$ & $.175^{*}$ & $(.114)$ & $.297^{*}$ & $(.181)$ \\
& & & & & & & & \\
B. From 8.4\% to 20\% & & & & & & & & \\
Language & .080 & $(.059)$ & .096 & $(.081)$ & $.123^{*}$ & $(.073)$ & $.316^{* *}$ & $(.151)$ \\
SocioEmotional & $.096^{*}$ & $(.054)$ & -.039 & $(.072)$ & $.165^{* *}$ & $(.069)$ & .026 & $(.105)$ \\
Motor & .056 & $(.049)$ & .002 & $(.071)$ & $.120^{*}$ & $(.064)$ & .048 & $(.121)$ \\
School & .050 & $(.041)$ & .028 & $(.052)$ & .055 & $(.061)$ & .147 & $(.099)$ \\
& & & & & & & & \\
C. From 20 \% to 40\% & & & & & & & & \\
Language & -.096 & $(.077)$ & .039 & $(.090)$ & -.110 & $(.099)$ & -.342 & $(.229)$ \\
SocioEmotional & $.132^{*}$ & $(.068)$ & .106 & $(.092)$ & .118 & $(.097)$ & .020 & $(.129)$ \\
Motor & -.041 & $(.079)$ & -.072 & $(.094)$ & .028 & $(.109)$ & -.067 & $(.144)$ \\
School & -.009 & $(.059)$ & .028 & $(.057)$ & -.034 & $(.101)$ & .007 & $(.124)$ \\
\hline
\end{tabular}

Notes: This table displays the results of three policy simulations. The first asks how increasing the supply of places in care centers from zero to the average level in our sample of children in center-based care ("From 0 to $8.4 \%$ "). The second simulation asks how expanding supply further up to $20 \%$ affects children's development outcomes ("From $8.4 \%$ to $20 \%$ "). The third simulation asks how providing 40 children instead of 20 with access to center-based care affects children's development ("From $20 \%$ to $40 \%$ "). Estimates are based on equation 8 including a third-order polynomial of the propensity score. Standard errors are shown in parentheses.

Source: school entrance examination, Schleswig-Holstein 2009-2011, our calculations.

MTEs.

\subsection{Policy Simulations and IV Results}

MTE estimates can be used in simulations of alternative reforms of the child care system. We report the results of three policy simulations. ${ }^{22}$ The first simulation increases the supply of child care places from zero to the average attendance rate in our sample, $8.4 \%$. The second simulation increases the supply further, from $8.4 \%$ to $20 \%$. This simulation resembles the latest expansion occurring in West Germany, which aimed at fulfilling the target set by the day care expansion law (the average attendance rate in West Germany in 2012 amounts to 18.3\%). Finally, we simulate a strong expansion of child care places, one that guarantees 4 out of 10 children a place in early care.

Table 7 provides the results of these simulations for all children as well as for the three

\footnotetext{
${ }^{22}$ See Appendix A for a concise description of the policy simulations and a discussion of the relationship between MTEs and linear IV. These policy experiments are only valid under some important restrictions. In particular, we suppose that increasing the supply of child care places will be possible without any general equilibrium effects. This assumption is likely to be satisfied for smaller expansions but is harder to justify for larger expansions.
} 
subgroups. There are remarkable gains for certain subgroups, especially for children of less educated mothers. For children of less educated mothers, for instance, an initial expansion of center-based care from zero coverage to the average attendance rate in our sample, $8.4 \%$, leads to gains of $33.9 \mathrm{ppts}$ in language skills, $19.5 \mathrm{ppts}$ in socio-emotional maturity, $23.1 \mathrm{ppts}$ in motor skills, and 17.5 ppts in school readiness. A further expansion to a coverage rate of $20 \%$ entails gains of 12.3 ppts in language skills, 16.5 ppts in socio-emotional maturity, and 12.0 ppts in motor skills, and and no significant gains in school readiness. However, with a further expansion up to $40 \%$ coverage, the estimated effects are insignificant for all development dimensions. In a similar vein, the gains in language skills observed for children with foreign parents quickly disappear when a certain coverage level is reached (100.4 ppts, 31.6 ppts, and zero gains for the alternative simulations, respectively).

These policy expansions are very much in line with the decreasing pattern of the MTEs documented in Figure 7. The fairly modest expansions provide early care to children who obtain large gains from attending center-based care. The strong expansion, in contrast, also provides care to children who experience low or zero MTEs. The three policy simulations show that heterogeneity in the MTE with respect to unobserved characteristics matters. As a consequence, one cannot simply extrapolate findings from one context to another but must rather consider which types of children occupy the places added by the refor $\mathrm{m}$.

Linear IV is a common estimator in the earlier literature on the effects of early care on child development. Table 8 presents linear IV estimates of the effects of center-based care on child development. Panel A reports estimates of the effects of early care on child development that use the average attendance rate as an instrument for individual care attendance. All estimates control for the full set of child, mother, care center, and regional characteristics. Estimates also include a full set of cohort and school district fixed effects. IV point estimates are positive and substantially larger than OLS point estimates. Early care improves socio-emotional maturity by 9.6 ppts and school readiness by 6.6 ppts. Effects on language and motor skills are also positive but are not significantly different from zero.

Panel B of Table 8 shows that effects for children with highly educated mothers are not significantly different from zero. In contrast, IV effects for children of less educated mothers are positive and significantly different from zero for three out of four skill domains (Panel C of Table 8). Socio-emotional maturity improves by 13.4 ppts, motor skill development by 8.5 ppts, and overall school readiness by 9.1 ppts. We put these effects in perspective by comparing them to the maternal education achievement gap. Children of highly educated mothers are 8.4 ppts less likely to have language problems, $7.1 \mathrm{ppts}$ less likely to have socio-emotional problems, 4.5 ppts less likely to have motor problems, and 5.8 ppts more likely to be ready for primary school than children with less educated mothers (see Table B.2 in Appendix B). The IV effects are large: early care can close the gap in child development between children of highly educated mothers 
Table 8: Linear IV Estimates

\begin{tabular}{lcccc}
\hline \hline & Language & Socio-Emotional & Motor & School Readiness \\
\hline A. All & & & & \\
Early Care (D) & 0.061 & $0.096^{* *}$ & 0.058 & $0.066^{* *}$ \\
& $(0.045)$ & $(0.038)$ & $(0.036)$ & $(0.032)$ \\
Adjusted R2 & 0.097 & 0.083 & 0.104 & 0.111 \\
Children & 36381 & 36381 & 36381 & 36381 \\
& & & & \\
B. Highly Educated & & & & \\
Early Care (D) & 0.082 & 0.032 & 0.020 & 0.015 \\
& $(0.058)$ & $(0.054)$ & $(0.052)$ & $(0.037)$ \\
Adjusted R2 & 0.079 & 0.073 & 0.109 & 0.079 \\
Children & 11008 & 11008 & 11008 & 11008 \\
& & & & \\
C. Less Educated & & & & \\
Early Care (D) & 0.065 & $0.134^{* * *}$ & $0.085^{*}$ & $0.091^{* *}$ \\
& $(0.053)$ & $(0.046)$ & $(0.044)$ & $(0.045)$ \\
Adjusted R2 & 0.090 & 0.082 & 0.102 & 0.107 \\
Children & 25373 & 25373 & 25373 & 25373 \\
& & & & \\
D. Foreign & & & & \\
Early Care (D) & $0.260^{* *}$ & 0.095 & 0.124 & $0.110^{*}$ \\
& $(0.110)$ & $(0.062)$ & $(0.076)$ & $(0.065)$ \\
Adjusted R2 & 0.136 & 0.090 & 0.092 & 0.148 \\
Children & 7531 & 7531 & 7531 & 7531 \\
\hline \hline
\end{tabular}

Notes: All estimates are based on IV estimations controlling for the full set of individual characteristics, care center characteristics, regional proxies of child care demand, and school district characteristics, as well as for a set of cohort and school district dummies. We instrument the individual child care attendance by the average attendance rate in the cohort and the district of residence. Inference is based on standard errors that allow for clustering at the school district level.

Source: school entrance examination, Schleswig-Holstein 2009-2011, our calculations 
and children of less educated mothers. Early care attendance can thus "level the playing field" between these two groups of children.

Panel D of Table 8 shows the IV estimates for children with at least one foreign parent. Effects are positive and significant for language skills (26.0 ppts) and school readiness (11.0 ppts). We put these effects in perspective by comparing them to the immigrant child achievement gap. Immigrant children are 9.4 ppts more likely to have language problems and 3 ppts less likely to be ready for primary school than native children (Table B.2 in Appendix B). Early care thus more than compensates for this development gap between immigrant and native children.

Linear IV estimates lie somewhere between the policy simulation that expands the supply of places from the average attendance rate in our sample (8.4\%) to a level of $20 \%$ and the policy simulation that expands the supply of places even further to a level of $40 \%$ (see Table 7 ). How can this be explained? Heckman and Vytlacil (2000) and Carneiro et al. (2011) show that the linear IV estimator is a weighted average of the underlying MTEs. Weights are large for children with intermediate values of the unobserved determinants of center-based care attendance (Figure A.1 in Appendix A). These children are served by an expansion of places in center-based care between $20 \%$ and $40 \%$. This explains why the linear IV results lie between the estimates of the second and third policy simulations. Linear IV estimates do not provide information on the effects of alternative policies. Understanding the effects of policy expansions requires knowledge of the underlying MTE.

\section{Conclusions}

Many OECD countries are undertaking substantial expansions of their child care systems. We study how attending child care early in life affects their skills later on. Our paper addresses this question using a marginal treatment effects (MTE) framework. This framework allows us to discuss the full range of heterogeneity in the effects of center-based care exposure depending on observed background characteristics as well as on unobserved determinants of care center attendance. In addition, the MTE framework allows us to simulate alternative reforms of the child care system.

Our main findings are as follows. First, there is substantial heterogeneity in the causal effects of early child care exposure on children's medium-term development. Effects tend to be stronger for children from disadvantaged backgrounds, in particular children of less educated mothers or children of foreign parents. Features of care center quality are also very important: effects are stronger for centers with smaller playgroups and older, better trained, and full-time staff. Second, we find evidence of a decreasing pattern of the effects of early exposure to center-based care with respect to unobserved determinants of center-based care attendance, pointing to a scenario of "selection on gains." Third, modest expansions of early center-based care availability 
improve child development outcomes for children from disadvantaged and foreign backgrounds, whereas a strong expansion has no significant effects. Fourth, conventional linear IV estimates are generally not informative about the effects of expanding child care places.

Are these results applicable to other contexts? Germany's expansion of early care was moderate in the past decade. Countries expanding early care more rapidly (such as Southern Europe and the Netherlands) or more slowly (such as the United States) might experience different effects of early care on child development. The German context is also unusual in maintaining a fairly high level of quality while expanding. This probably explains why we find positive effects of early care in contrast to the negative effects found for a Canadian expansion (Baker et al., 2008). Finally, German mothers of young children who work are called "raven mothers", reflecting a strong social stigma against working while children are still young. While this stigma probably explains why Germany has been slow to embrace the need for early care, it has lost its clout in recent years.

Regardless of external validity, our results highlight three points. First, the same type of policy can have very different effects on children depending on their own characteristics and on the characteristics of the alternative care modes. Thus, policy assessments of early care expansions need to pay particular attention to the question of who is already in care and who will start attending care following an expansion of the system. Second, accounting for care center quality matters: analyses that ignore care center quality underestimate the causal effects of center-based care. Third, knowledge of the MTEs is crucial to assess how an expansion of the child care system will affect the children occupying the newly created places. The conventional estimation approach, linear IV, does not provide a shortcut for policy assessments of reforms based on MTE estimates. 


\section{References}

Algan, Y., Dustmann, C., Glitz, A., and Manning, A. (2010). The economic situation of firstand second-generation immigrants in france, germany, and the uk. The Economic Journal, 120(542), F4-F30.

Baker, M. and Milligan, K. (2012). Maternity leave and children's cognitive and behavioral development. Nber working paper, NBER.

Baker, M., Gruber, J., and Milligan, K. (2008). Universal child care, maternal labor supply, and family well-being. Journal of Political Economy, 116(4), 709-745.

Baum, C. (2003). Does early maternal employment harm child development? an analysis of the potential benefits of leave taking. Journal of Labor Economics, 21(2).

Berlinski, S., Galiani, S., and Gertler, P. (2009). The effect of pre-primary education on primary school performance. Journal of Public Economics, 93(1-2), 219-234.

Bitler, M., Hoynes, H., and Domina, T. (2013). Experimental evidence on distributional effects of head start. Technical report, UC Berkeley.

Bjorklund, A. and Moffitt, R. (1987). The Estimation of Wage Gains and Welfare Gains in Self-selection. The Review of Economics and Statistics, 69(1), 42-49.

Black, S. E., Devereux, P. J., Loken, K. V., and Salvanes, K. G. (2014). Care or cash? the effect of child care subsidies on student performance. Review of Economics and Statistics.

Blau, D. and Currie, J. (2006). Who is minding the kids. The Handbook of Education Economics.

Blau, F. and Grossberg, A. (1992). Maternal labor supply and children's cognitive development. Review of Economics and Statistics, 77, 231-249.

Brinch, C. N., Mogstad, M., and Wiswall, M. (2014). Beyond late with a discrete instrument: Heterogeneity in the quantity-quality interaction of children. Working paper, University of Chicago.

Brooks-Gunn, J., Han, W.-J., and Waldfogel, J. (2002). The effects of early maternal employment on child cognitive development. Demography, 39(2), 369-92.

Bucarey, A., Ugarte, G., and Urzua, S. (2014). El efecto de la educacion preescolar en chile. Technical report, mimeo.

Carneiro, P., Heckman, J., and Vytlacil, E. (2011). Estimating marginal returns to education. American Economic Review, 101, 2754-2781. 
Carneiro, P., Loken, K., and Salvanes, K. G. (2014). A flying start? long term consequences of time investments in infants in their first year of life. Journal of Political Economy.

Cascio, E. (2009). Do investments in universal early education pay off? long-term effects of introducing kindergartens into public schools. Working Paper 14951, NBER.

Chetty, R., Friedman, J. N., Hilger, N., Saez, E., Schanzenbach, D. W., and Yagan, D. (2011). How does your kindergarten classroom affect your earnings? evidence from project star. The Quarterly Journal of Economics, 126(4), 1593-1660.

Cunha, F. and Heckman, J. (2007). The technology of skill formation. American Economic Review, 97, 31-47.

Dahl, G. and Lochner, L. (2012). The impact of family income on child achievement: Evidence from changes in the earned income tax credit. American Economic Review, 102(5), 19271956.

Dale, S. B. and Krueger, A. B. (2002). Estimating the payoff to attending a more selective college: An application of selection on observables and unobservables. The Quarterly Journal of Economics, 117(4), 1491-1527.

Datta-Gupta, N. and Simonsen, M. (2010). Non-cognitive child outcomes and universal high quality child care. Journal of Public Economics, 94(1-2), 30-43.

Davis-Kean, P. (2005). The influence of parent education and family income on child achievement: The indirect role of parental expectations and the home environment. Journal of Family Psychology, 19(2), 294-304.

Doyle, Joseph J., J. (2007). Child protection and child outcomes: Measuring the effects of foster care. American Economic Review, 97(5), 1583-1610.

Drange, N., Havnes, T., and Sandsor, A. (2014). Kindergarten for all: Long run effects of a universal intervention. mimeo, Statistics Norway.

Dustmann, C. and Schoenberg, U. (2012). The effect of expansions in maternity leave coverage on children's long-term outcomes. American Economic Journal: Applied Economics.

Dustmann, C., Raute, A., and Schoenberg, U. (2013). Does universal child care matter? evidence from a large expansion in pre-school education. mimeo, UCL.

Felfe, C. (2012). The child penalty - what about job amenities? Labour Economics, 19(1), $59-67$. 
Felfe, C. and Lalive, R. (2012). Early child care and child development: For whom it works and why. Discussion paper 7100, IZA.

Felfe, C., Nollenberger, N., and Rodriguez-Planas, N. (2014). Can’t buy mommy's love? universal child care and children's long-run cognitive development. Journal of Population Economics.

Fitzpatrick, M. D. (2008). Starting school at four: The effect of universal pre-kindergarten on children's academic achievement. The B.E. Journal of Economic Analysis 83 Policy, 8(1), 46.

French, E. and Song, J. (2014). The effect of disability insurance receipt on labor supply: A dynamic analysis. American Economic Journal: Policy.

Gonzalez, L. (2013). The effects of a universal child benefit. American Economic Journal: Economic Policy, 5(3).

Goodman, R. N. (1997). The strengths and difficulties questionnaire: A research note. Journal of Child Psychology and Psychiatry, (38), 581-586.

Gormley Jr., W. T., Phillips, D., and Gayer, T. (2008). THE EARLY YEARS: Preschool Programs Can Boost School Readiness. Science, 320(5884), 1723-1724.

Havnes, T. and Mogstad, M. (2011). No child left behind: Universal child care and children's long-run outcomes. American Economic Journal: Economic Policy, 3(2), 97-129.

Havnes, T. and Mogstad, M. (2014). Is universal child care leveling the playing field? evidence from non-linear difference-in-differences. Journal of Public Economics.

Heckman, J. and Masterov, D. (2007). The productivity argument for investing in young children. Science, 29(3), 446-493.

Heckman, J. and Vytlacil, E. (1999). Local instrumental variables and latent variable models for identifying and bounding treatment effects. Proceedings of the National Academy of Sciences, 96(8), 4730-34.

Heckman, J. and Vytlacil, E. (2001). Policy relevant treatment effects. American Economic Review, 91(2), 107-11.

Heckman, J. and Vytlacil, E. (2005). Structural equation, treatment effects, and econometric policy evaluation. Econometrica, 73(3), 669-738.

Heckman, J. and Vytlacil, E. (2007a). Econometric evaluation of social programs, part i: Causal models, structural models and econometric policy evaluations. In J. Heckman and E. Leamer, editors, Handbook of the Econometrics, volume 6B, pages 4779-4874, New York. 
Heckman, J. and Vytlacil, E. (2007b). Econometric evaluation of social programs, part ii: Using the marginal treatment effect to organize alternative econometric estimators to evaluate social programs and to forecast their effects in new environments. In J. Heckman and E. Leamer, editors, Handbook of the Econometrics, volume 6B, pages 4875-5144, New York.

Heckman, J. and Vytlacil, E. J. (2000). Local instrumental variables. NBER Technical Working Papers 0252, National Bureau of Economic Research, Inc.

Heckman, J. J., Moon, S. H., Pinto, R., Savelyev, P. A., and Yavitz, A. (2010). The rate of return to the HighScope Perry Preschool Program. Journal of Public Economics, 94(1-2), $114-128$.

Hsin, A. and Felfe, C. (2014). When does time matter? maternal employment and children's time with parents and child development. Demography.

Huesken, K. (2010). Kita vor ort: Betreuungsatlas auf ebene der jugendamtsbezirke 2010. Deutsches Jugendinstitut e.V.

James-Burdumy, S. (2005). The effect of maternal labor force participation on child development. Journal of Labor Economics, 23(1), 177-211.

Krueger, A. B. and Whitmore, D. M. (2001). The effect of attending a small class in the early grades on college-test taking and middle school test results: Evidence from project star. The Economic Journal, 111(468), 1-28.

Linver, M., Brooks-Gunn, J., and Kohen, D. (2002). Family processes as pathways from income to young childrens development. Developmental Psychology, 38, 719734.

Liu, Q. and Skans, O. (2010). The duration of paid parental leave and children's scholastic performance. B.E. Journal of Economic Analysis and Policy (contributions), 10(1), 3.

Maestas, N., Mullen, K. J., and Strand, A. (2013). Does disability insurance receipt discourage work? using examiner assignment to estimate causal effects of ssdi receipt. American Economic Review, 103(5), 1797-1829.

Magnuson, K. A., Ruhm, C. J., and Waldfogel, J. (2007). Does Prekindergarten Improve School Preparation and Performance? Economics of Education Review, 26, 33-51.

Manski, C. F. (1993). Identification of Endogenous Social Interactions: The Reflection Problem. Review of Economic Studies, 60(3), 531-542.

Noboa Hidalgo, G. and Urzúa, S. (2012). The effect of participation in public childcare centers: Evidence from chile. Journal of Human Capital, 6(1). 
OECD (2014). Oecd enrollment in child care and pre-school statistics. Technical report, OECD Paris.

Roy, A. D. (1951). Some thoughts on the distribution of earnings. Oxford Economic Papers, 3(2), 135-146.

Ruhm, C. (2004). Parental employment and child cognitive development. Journal of Human Resources, 39(1), 155-192.

Walters, C. (2014). Inputs in the production of early-childhood human capital: Evidence from head start. Technical report, UC Berkeley.

Wuertz-Rasmussen, A. (2010). Increasing the length of parents' birth-related leave : The effect on children's long-term educational outcomes. Labour Economics, 17(1), 91-100.

Yeung, J., Linver, M., and Brooks-Gunn, J. (2002). How money matters for young children's development: Parental investment and family processes. Child Development, $\mathbf{7 3}, 1861$. 


\section{A Using MTE to Recover Treatment Parameters}

\section{A.1 Policy-Relevant Treatment Effects}

Following Heckman and Vytlacil (2001, 2005, 2007b), we consider different policies that change the probability of participating in child care but do not affect potential outcomes directly. In particular, we assess the effects of: 1 . expanding the number of available child care places from its current level to a level that accommodates $30 \%$ of all children, and 2. expanding the number of child care places from $30 \%$ to $70 \%$.

Setting the supply of child care to $z^{\prime}$ places per 100 children changes the probability of attending child care, i.e., $p^{\prime}=\operatorname{Prob}\left(D=1 \mid X=x, Z=z^{\prime}\right) \neq p=\operatorname{Prob}(D=1 \mid X=x, Z=z)$ where $z$ refers to the lower level of places per 100 children observed in the data and $z^{\prime}$ corresponds to the higher level of places per 100 children. For instance, $z$ is equal to the level observed in the data and $z^{\prime}$ is equal to $30 \%$ under policy 1 . $z$ is equal to $30 \%$ and $z^{\prime}$ is equal to $70 \%$ under policy 2 .

One can then predict the expected value of outcome $s$ after policy implementation $\left(y^{\prime}=\right.$ $\left.E\left(Y^{s} \mid X=x, P(W)=p^{\prime}\right)\right)$ and contrast it to the counterfactual outcome $\left(y=E\left(Y^{s} \mid X=\right.\right.$ $x, P(W)=p))$ without the policy. Heckman and Vytlacil $(2005,2007 \mathrm{a})$ show that the treatment impact of the policy for children with characteristics $X$ and propensity score $p$ corresponds to the policy-relevant treatment effect and can be expressed as follows:

$$
\frac{E\left(Y^{s} \mid X=x, P(Z)=p^{\prime}\right)-E\left(Y^{s} \mid X=x, P(Z)=p\right)}{E\left(D \mid X=x, P(Z)=p^{\prime}\right)-E(D \mid X=x, P(Z)=p)}
$$

We calculate this treatment effect in two steps. We first form the conditional version of the treatment effect. We then aggregate the conditional treatment effect. Inference is based on the block bootstrap (within school districts).

\section{A.2 Linear Instrumental Variable Estimates}

As established by Heckman and Vytlacil (1999, 2000, 2005, 2007a,b), any parameter can be constructed by aggregating MTE and using the appropriate weights. The general formula is

$$
\operatorname{PAR}(x)=\int_{0}^{1} \operatorname{MTE}(x, u) h_{P A R}(x, u) d u
$$

Using the propensity score as an instrument for child care attendance, the linear instrumental variable estimator aggregates MTE using the following weights:

$$
h_{I V}=\left[\int_{u}^{1}(p-E(P \mid X=x)) f(p \mid X=x) d p\right] \frac{1}{\operatorname{Var}(P \mid X=x)}
$$


Figure A.1: Linear IV weights

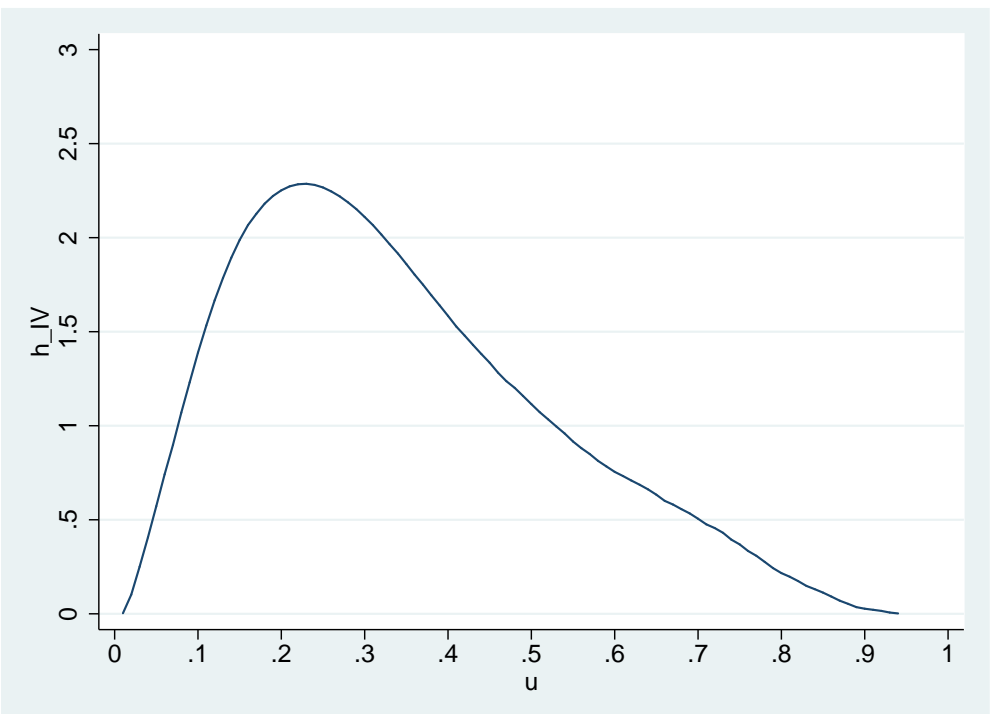

Notes: This graph reports the weights implicit in linear IV, h_IV.

Source: school entrance examination, Schleswig-Holstein 2009-2011, our calculations

Thus, the linear IV estimate contrasts observations above and below the mean propensity score and weights observations with respect to the inverse of the variance of $P$. The weights will be 0 at 0 or 1 and give greater weight to observations in the middle. The linear IV weights therefore put a lot of weight on children with high values of $u$. Figure A.1 displays the distribution of the IV weights for our first stage (the propensity to attend child care using local supply as the instrument) along the entire range of the "unobserved component" of the propensity score. 


\section{B Additional Tables and Figures}

Figure B.1: Individual vs. Average Attendance

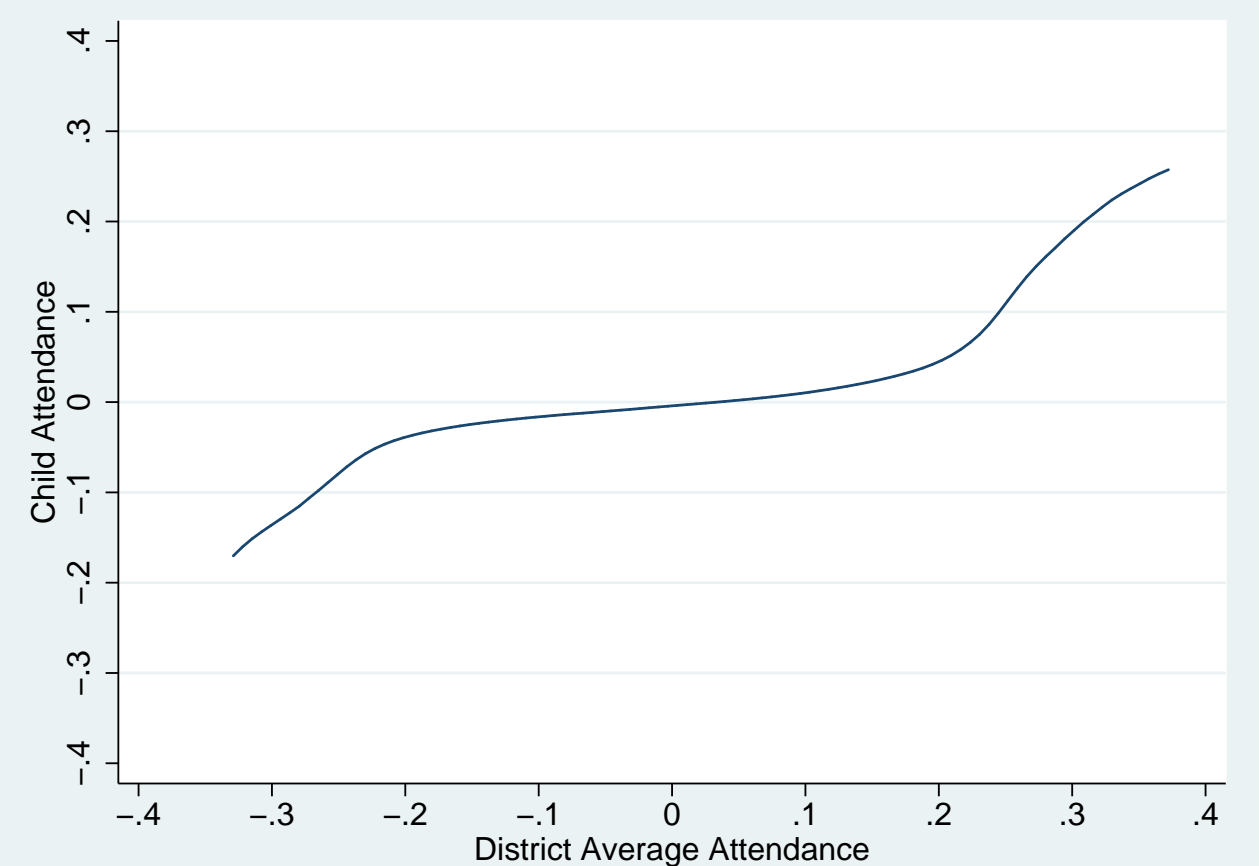

Notes: Epanechnikov Kernel regression with 0.25 bandwidth. Both children's early care attendance and school district attendance are expressed as deviations from school district means. 
Figure B.2: Slope of Child Development vs Average Attendance
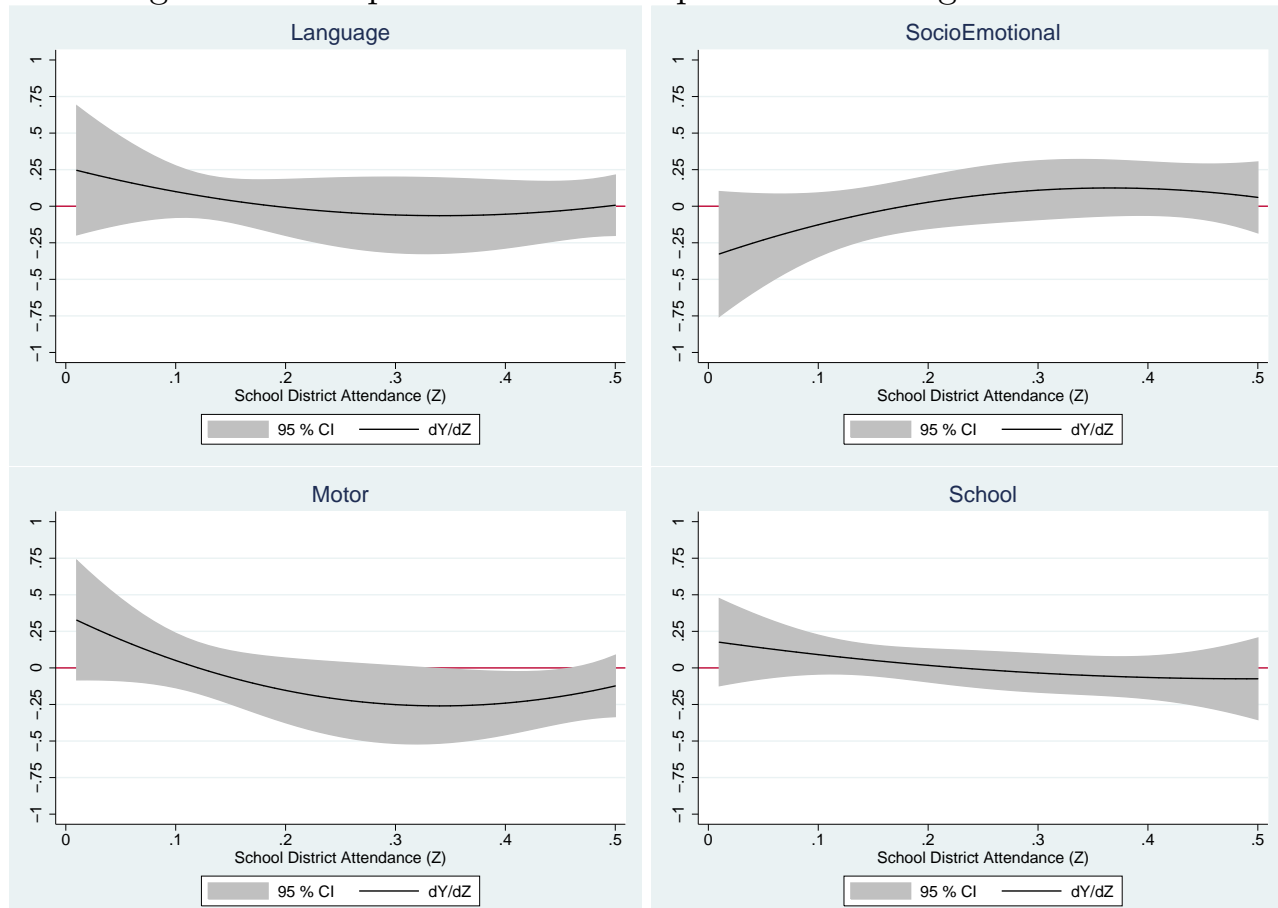

Notes: The graph plots the derivative of the mean child development outcome with respect to the average attendance rate, along with the $95 \%$ confidence interval. The derivative estimate is based on a third-order polynomial specification of mean child development outcome and school district attendance. Estimates are clustered by school district and include cohort and school district fixed effects. 
Figure B.3: MTE $-3^{\text {rd }}$ vs $5^{\text {th }}$ order polynomial

A. Language Skills

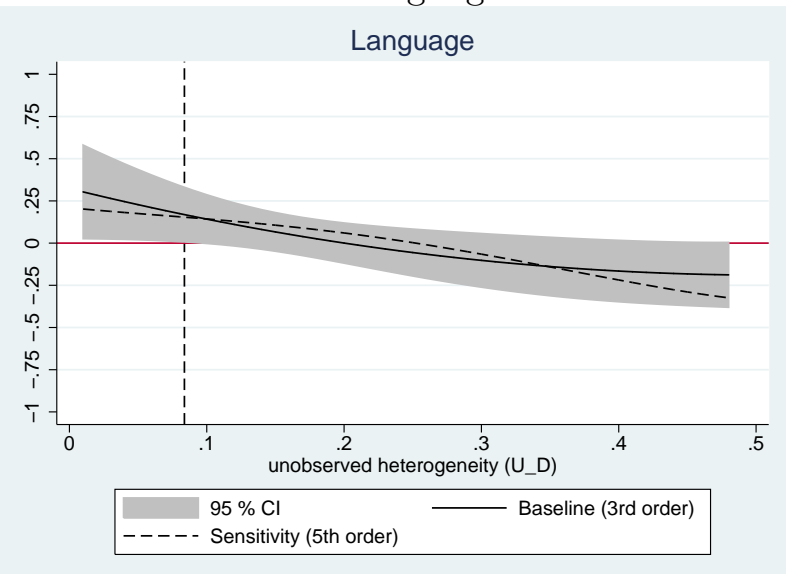

C. Motor Skills

Motor

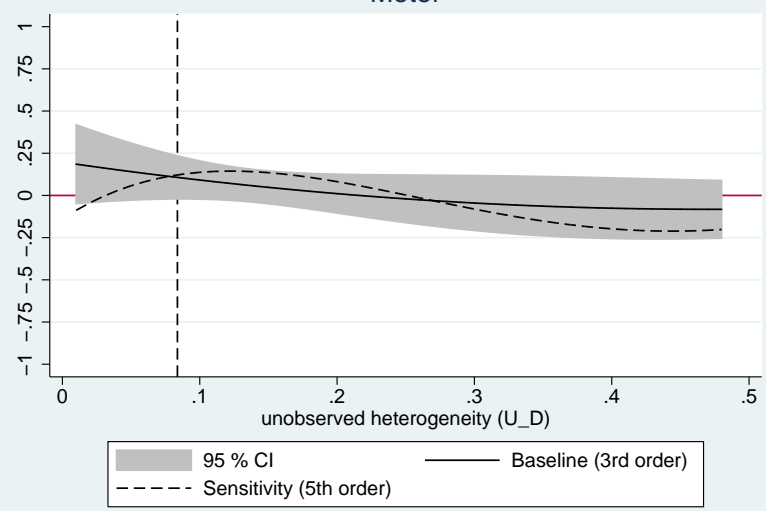

B. Socio-Emotional Maturity

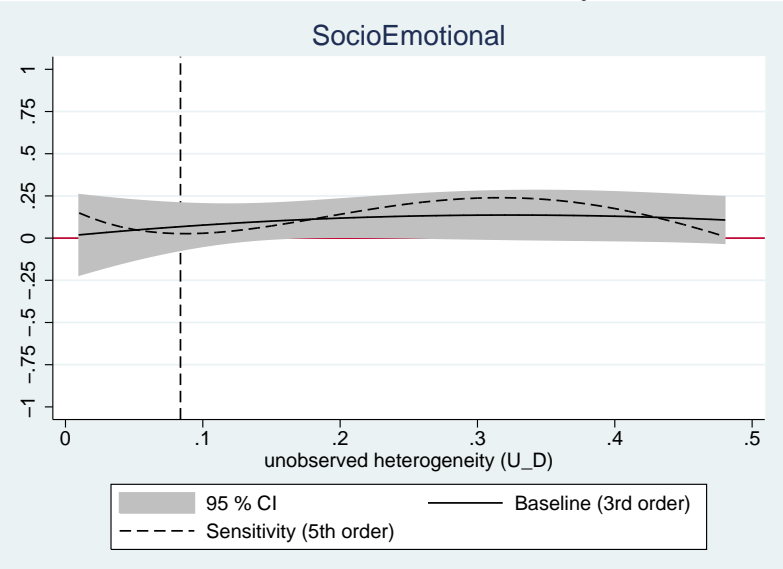

D. School Readiness

School

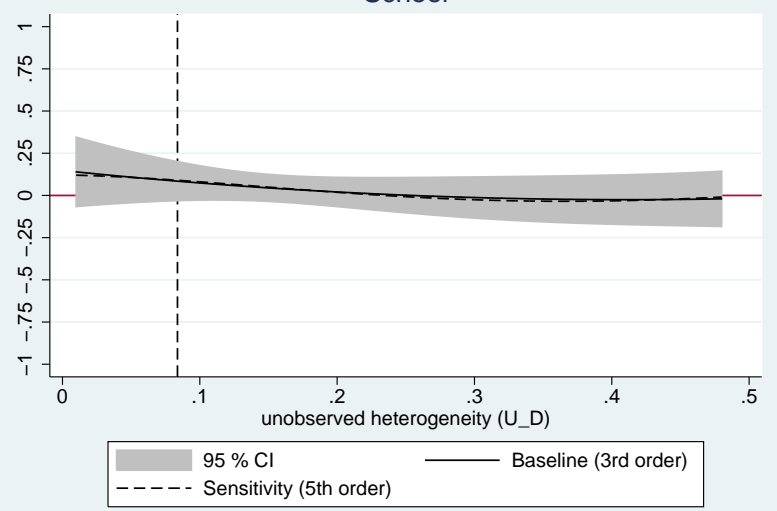

Notes: The graph plots the MTE for the average child as a function of unobserved determinants, $U_{D}$ (solid line), along with the $95 \%$ confidence interval (shaded area). The solid line uses a polynomial of order 3 to estimate the MTE. The dashed line uses a polynomial of order 5 to estimate the MTE. Estimates use variation in district attendance as instruments for individual attendance. Vertical dashed line indicates the average probability of being in early care.

Source: school entrance examination, Schleswig-Holstein 2009-2011, our calculations. 
Figure B.4: MTE aggregated from Subgroup Analysis

A. Language Skills

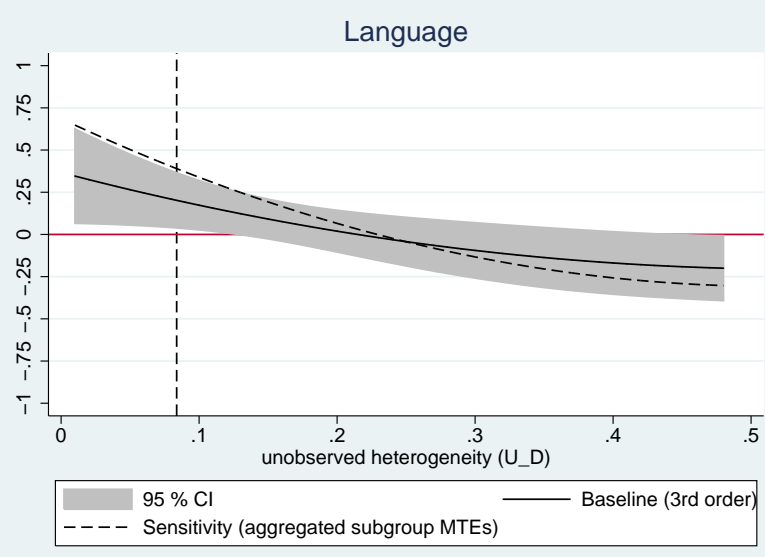

C. Motor Skills

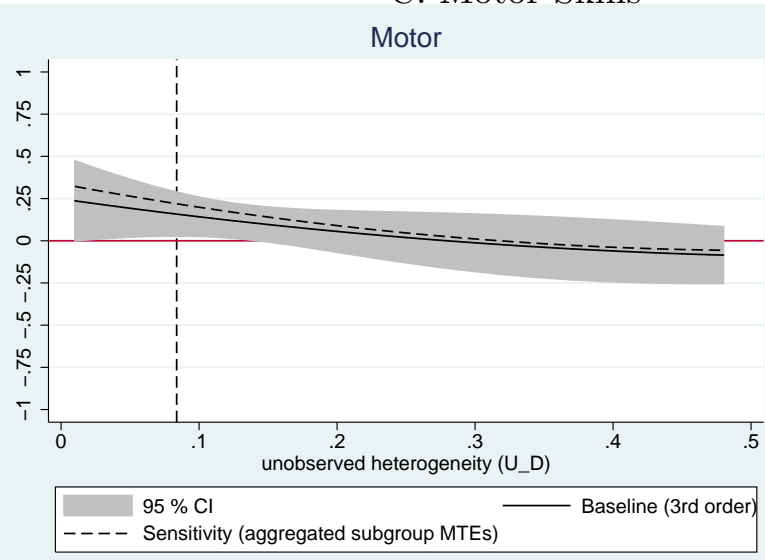

B. Socio-Emotional Maturity

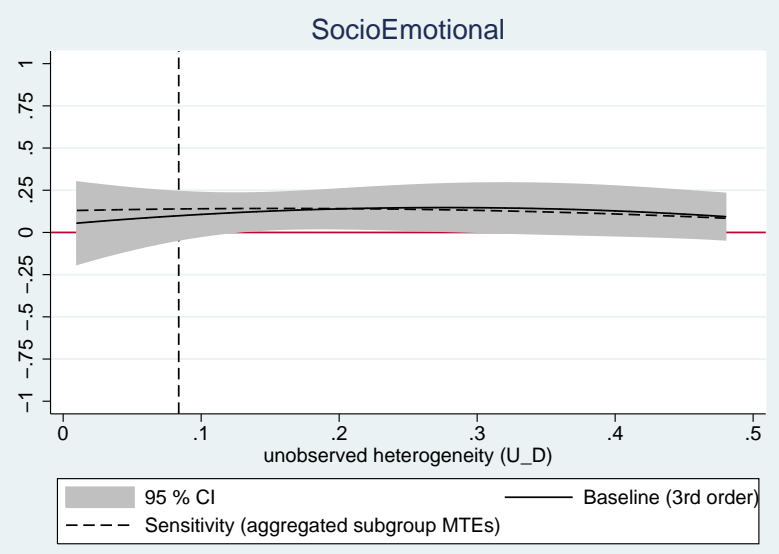

D. School Readiness

School

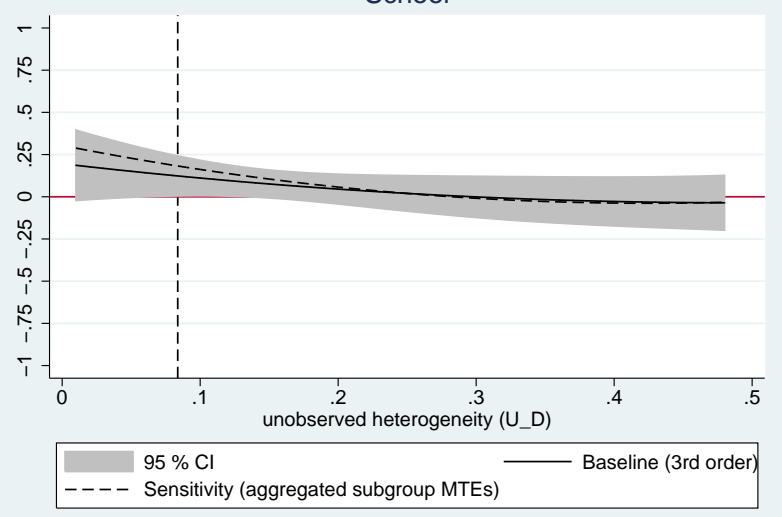

Notes: The graph plots the MTE for the average child as a function of unobserved determinants, $U_{D}$, along with the $95 \%$ confidence interval (shaded area). The solid line corresponds to our baseline MTEs, relying on the assumption of no heterogeneity in the unobserved component of the MTEs (assumption). The dashed lines are aggregates of the MTEs resulting from subgroup analysis (samples of children of highly educated mothers, less educated mothers, and foreign parents). Estimates use variation in the average attendance rate as instruments for individual attendance. The vertical dashed line indicates the average probability of being in early care.

Source: administrative data/school entrance examination, our calculations. 
Figure B.5: MTE with and without Care Center-Quality Measures

A. Language Skills

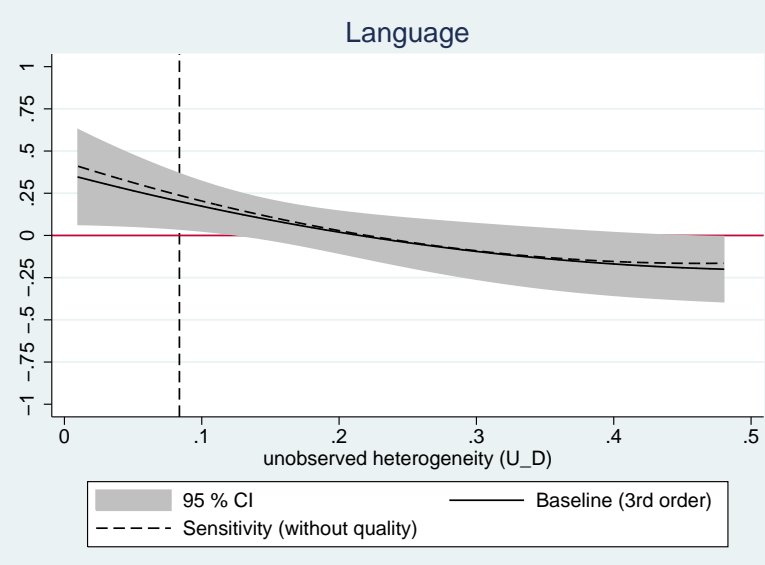

C. Motor Skills

Motor

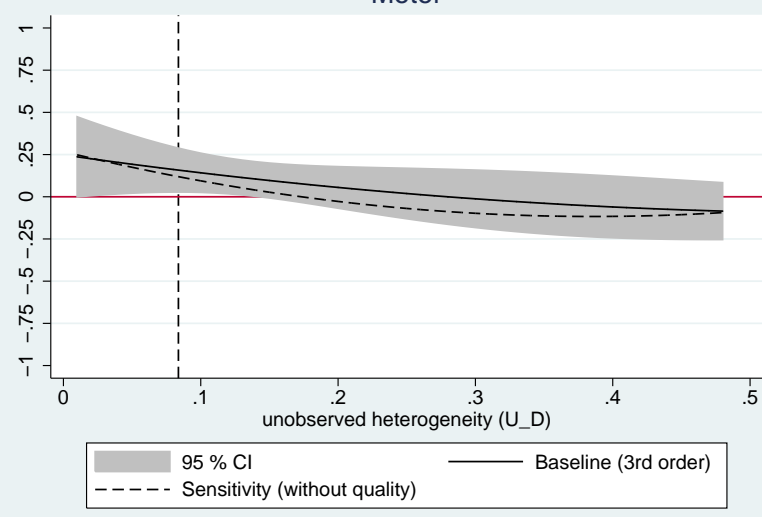

B. Socio-Emotional Maturity

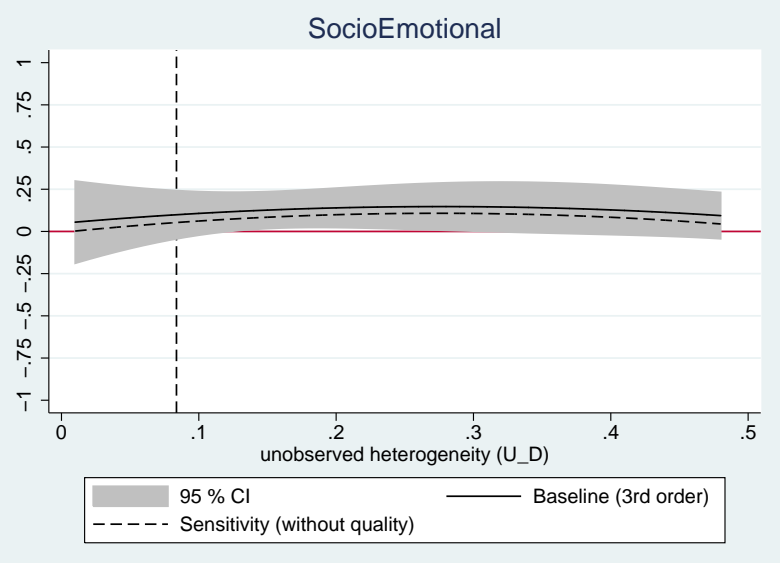

D. School Readiness

School

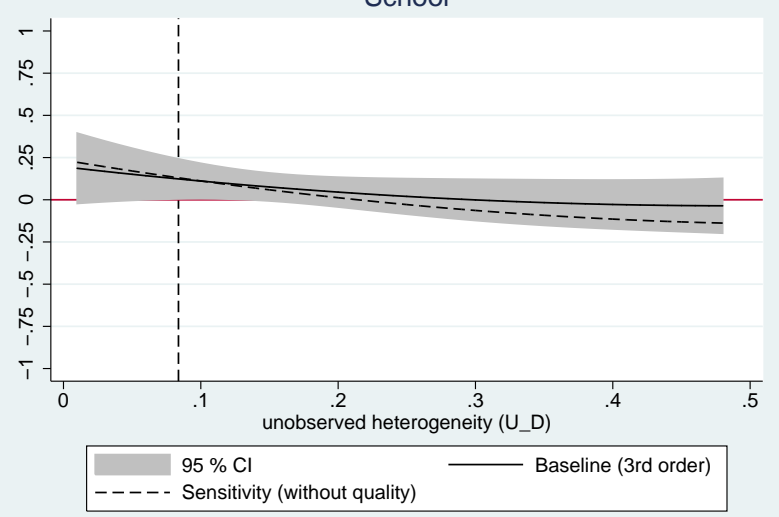

Notes: The graph plots the MTE for the average child as a function of unobserved determinants, $U_{D}$, along with the $95 \%$ confidence interval (shaded area). The solid line controls for the set of center quality features when estimating the MTE. The dashed line omits the set of center quality variables when estimating the MTE. Estimates use variation in the average attendance rate as instruments for individual attendance. The vertical dashed line indicates the average probability of being in early care. Source: administrative data/school entrance examination, our calculations. 
Table B.1: Estimates of the propensity score

\begin{tabular}{|c|c|}
\hline District Attendance $(\mathrm{Z})$ & $\begin{array}{c}1.479^{* * *} \\
(0.067)\end{array}$ \\
\hline Z pw 2 & $\begin{array}{c}-3.495^{* * *} \\
(0.351)\end{array}$ \\
\hline Z pw 3 & $\begin{array}{c}3.012^{* * *} \\
(0.446)\end{array}$ \\
\hline Cohort 2010 (D) (d) & $\begin{array}{l}-0.000 \\
(0.003)\end{array}$ \\
\hline Cohort 2011 (D) (d) & $\begin{array}{c}0.014 \\
(0.011)\end{array}$ \\
\hline Child Age (Months) & $\begin{array}{c}-0.004^{* * *} \\
(0.000)\end{array}$ \\
\hline Boy (D) (d) & $\begin{array}{c}0.001 \\
(0.002)\end{array}$ \\
\hline Low Birth Weight (D) (d) & $\begin{array}{c}-0.014^{* * *} \\
(0.004)\end{array}$ \\
\hline Foreign (D) (d) & $\begin{array}{c}-0.010^{* * *} \\
(0.003)\end{array}$ \\
\hline Number of Siblings & $\begin{array}{c}-0.013^{* * *} \\
(0.001)\end{array}$ \\
\hline Mother is Single (D) (d) & $\begin{array}{c}0.015^{* * *} \\
(0.004)\end{array}$ \\
\hline Mother Has Tertiary Education (D) (d) & $\begin{array}{c}0.021^{* * *} \\
(0.003)\end{array}$ \\
\hline Mother Education Missing (D) (d) & $\begin{array}{l}-0.000 \\
(0.005)\end{array}$ \\
\hline Group Size (Children) & $\begin{array}{c}0.001 \\
(0.001)\end{array}$ \\
\hline Staff Age (Years) & $\begin{array}{c}-0.037^{* *} \\
(0.015)\end{array}$ \\
\hline Staff With Degree (\%) & $\begin{array}{c}-0.002 \\
(0.001)\end{array}$ \\
\hline Full-Time Staff (\%) & $\begin{array}{c}0.000 \\
(0.001)\end{array}$ \\
\hline Full-Time Children (\%) & $\begin{array}{c}-0.001^{* * *} \\
(0.000)\end{array}$ \\
\hline GDP per Capita & $\begin{array}{c}-0.008^{* *} \\
(0.003)\end{array}$ \\
\hline Female Employment Rate (\%) & $\begin{array}{c}-0.003 \\
(0.004)\end{array}$ \\
\hline Unemployment Rate (\%) & $\begin{array}{c}0.000 \\
(0.000)\end{array}$ \\
\hline Log Children in County 0-2 Years & $\begin{array}{c}-0.202^{* *} \\
(0.102)\end{array}$ \\
\hline Migration Rate (\%) & $\begin{array}{c}0.000 \\
(0.001)\end{array}$ \\
\hline Log Children in School District Cohort & $\begin{array}{c}0.002 \\
(0.003)\end{array}$ \\
\hline Boys (Fract) & $\begin{array}{c}-0.001 \\
(0.009)\end{array}$ \\
\hline Low Birth Weight (Fract) & $\begin{array}{c}0.053^{* * *} \\
(0.020)\end{array}$ \\
\hline Foreign (Fract) & $\begin{array}{c}0.014 \\
(0.011)\end{array}$ \\
\hline Number of Siblings (Avg) & $\begin{array}{c}0.014^{* * *} \\
(0.004)\end{array}$ \\
\hline Singe Mothers (Fract) & $\begin{array}{c}-0.039^{* * *} \\
(0.014)\end{array}$ \\
\hline Mother Has Tertiary Education (Fract) & $\begin{array}{c}-0.041^{* * *} \\
(0.010)\end{array}$ \\
\hline Mother Education Missing (Fract) & $-0.024^{* * *}$ \\
\hline
\end{tabular}


Table B.1 - continued

\begin{tabular}{lc}
\hline \hline & $(0.008)$ \\
County FE & No \\
District FE & Yes \\
Z terms (Chi2) & 3008.0 \\
Individual Variables (p-Value) & 0.000 \\
Quality Variables (p-Value) & 0.004 \\
District Variables (p-Value) & 0.000 \\
County Variables (p-Value) & 0.012 \\
log Likelihood & -8656.5 \\
Children & 36381 \\
\hline \hline
\end{tabular}

Notes: This table shows marginal effects resulting from probit model estimates of the propensity score. Estimates also include a full set of school district dummies and a constant term. Standard errors are clustered at the school district level and are shown in parenthesis: ${ }^{*} \mathrm{p}<0.10, * * \mathrm{p}<0.05, * * * \mathrm{p}<0.010$.

Source: school entrance examination Schleswig-Holstein 2009-2011, our calculations 
Table B.2: Full MTE Results

\begin{tabular}{|c|c|c|c|c|}
\hline & Language & SocioEmotional & Motor & School \\
\hline pZ Score & $\begin{array}{c}0.323^{* *} \\
(0.151)\end{array}$ & $\begin{array}{c}0.012 \\
(0.130)\end{array}$ & $\begin{array}{c}0.197 \\
(0.128)\end{array}$ & $\begin{array}{c}0.148 \\
(0.112)\end{array}$ \\
\hline \multirow[t]{2}{*}{$(\mathrm{pZ} \text { Score })^{2}$} & $-1.004^{*}$ & 0.387 & -0.591 & -0.421 \\
\hline & $(0.559)$ & $(0.501)$ & $(0.517)$ & $(0.429)$ \\
\hline \multirow[t]{2}{*}{$(\mathrm{pZ} \text { Score })^{3}$} & 0.655 & -0.398 & 0.417 & 0.341 \\
\hline & $(0.514)$ & $(0.488)$ & $(0.462)$ & $(0.409)$ \\
\hline \multirow[t]{2}{*}{ pZ $*$ Child Age } & -0.006 & $0.012^{*}$ & 0.008 & -0.005 \\
\hline & $(0.006)$ & $(0.007)$ & $(0.006)$ & $(0.005)$ \\
\hline \multirow[t]{2}{*}{$\mathrm{pZ} *$ Boy } & 0.004 & 0.020 & -0.021 & 0.019 \\
\hline & $(0.041)$ & $(0.039)$ & $(0.049)$ & $(0.034)$ \\
\hline \multirow[t]{2}{*}{$\mathrm{pZ} *$ low Birth Weight } & -0.018 & -0.085 & -0.076 & -0.120 \\
\hline & $(0.111)$ & $(0.106)$ & $(0.119)$ & $(0.113)$ \\
\hline \multirow[t]{2}{*}{$\mathrm{pZ} *$ Foreign } & -0.001 & -0.035 & -0.035 & $0.101^{* *}$ \\
\hline & $(0.079)$ & $(0.046)$ & $(0.049)$ & $(0.045)$ \\
\hline \multirow[t]{2}{*}{ pZ $*$ Number of Siblings } & -0.016 & 0.028 & 0.041 & 0.011 \\
\hline & $(0.028)$ & $(0.020)$ & $(0.027)$ & $(0.021)$ \\
\hline \multirow[t]{2}{*}{$\mathrm{pZ} *$ Mother is Single } & 0.032 & 0.030 & 0.028 & -0.005 \\
\hline & $(0.068)$ & $(0.069)$ & $(0.065)$ & $(0.053)$ \\
\hline \multirow[t]{2}{*}{ pZ * Mother has Higher Education } & -0.022 & $-0.067^{*}$ & -0.018 & 0.049 \\
\hline & $(0.042)$ & $(0.038)$ & $(0.043)$ & $(0.038)$ \\
\hline \multirow[t]{2}{*}{ pZ*missing Mom's Education } & -0.059 & -0.041 & -0.065 & 0.000 \\
\hline & $(0.063)$ & $(0.057)$ & $(0.065)$ & $(0.062)$ \\
\hline \multirow[t]{2}{*}{ pZ $*$ Children in Group } & -0.037 & 0.014 & $-0.070 * * *$ & -0.002 \\
\hline & $(0.032)$ & $(0.024)$ & $(0.021)$ & $(0.019)$ \\
\hline \multirow[t]{2}{*}{ pZ * Staff Age (Years) } & $0.099 *$ & 0.044 & $0.134^{* *}$ & $0.079^{*}$ \\
\hline & $(0.058)$ & $(0.060)$ & $(0.053)$ & $(0.046)$ \\
\hline \multirow[t]{2}{*}{$\mathrm{pZ} *$ Trained Staff $(\%)$} & 0.014 & 0.002 & $0.021^{* *}$ & 0.002 \\
\hline & $(0.010)$ & $(0.010)$ & $(0.009)$ & $(0.008)$ \\
\hline \multirow[t]{2}{*}{ pZ * Staff Full-Time (\%) } & 0.000 & 0.003 & 0.006 & $0.017^{* * *}$ \\
\hline & $(0.010)$ & $(0.007)$ & $(0.006)$ & $(0.006)$ \\
\hline \multirow[t]{2}{*}{ pZ * Child Full-Time (\%) } & $0.008^{* *}$ & -0.005 & 0.000 & $-0.005^{*}$ \\
\hline & $(0.003)$ & $(0.004)$ & $(0.003)$ & $(0.003)$ \\
\hline \multirow[t]{2}{*}{ Cohort 2010 (D) } & $-0.031^{* *}$ & $-0.033^{* * *}$ & $-0.026 * * *$ & $-0.036^{* * *}$ \\
\hline & $(0.013)$ & $(0.010)$ & $(0.009)$ & $(0.009)$ \\
\hline Cohort 2011 (D) & 0.040 & $-0.046^{*}$ & $-0.126 * * *$ & $-0.171^{* * *}$ \\
\hline & $(0.029)$ & $(0.027)$ & $(0.026)$ & $(0.025)$ \\
\hline Child Age (Months) & $0.014^{* * *}$ & $0.008^{* * *}$ & $0.014^{* * *}$ & $0.017^{* * *}$ \\
\hline & $(0.001)$ & $(0.001)$ & $(0.001)$ & $(0.001)$ \\
\hline Boy (D) & $-0.078 * * *$ & $-0.098 * * *$ & $-0.163^{* * *}$ & $-0.087 * * *$ \\
\hline & $(0.006)$ & $(0.006)$ & $(0.007)$ & $(0.006)$ \\
\hline Low Birth Weight (D) & $-0.063^{* * *}$ & $-0.075^{* * *}$ & $-0.099 * * *$ & $-0.124^{* * *}$ \\
\hline & $(0.012)$ & $(0.012)$ & $(0.012)$ & $(0.013)$ \\
\hline Foreign (D) & $-0.094^{* * *}$ & $0.031^{* * *}$ & $0.018^{* * *}$ & $-0.030 * * *$ \\
\hline & $(0.016)$ & $(0.008)$ & $(0.007)$ & $(0.008)$ \\
\hline Number of Siblings & $-0.023^{* * *}$ & -0.003 & $-0.007^{* *}$ & $-0.021 * * *$ \\
\hline & $(0.003)$ & $(0.003)$ & $(0.003)$ & $(0.003)$ \\
\hline Mother is Single (D) & $-0.038^{* * *}$ & $-0.082^{* * *}$ & $-0.048 * * *$ & $-0.052^{* * *}$ \\
\hline & $(0.010)$ & $(0.010)$ & $(0.010)$ & $(0.009)$ \\
\hline Mother Has Tertiary Education (D) & $0.084^{* * *}$ & $0.071^{* * *}$ & $0.045^{* * *}$ & $0.058^{* * *}$ \\
\hline & $(0.007)$ & $(0.007)$ & $(0.006)$ & $(0.006)$ \\
\hline Mother Education Missing (D) & -0.011 & 0.003 & -0.007 & $-0.029 * * *$ \\
\hline & $(0.010)$ & $(0.009)$ & $(0.008)$ & $(0.008)$ \\
\hline Group Size (Children) & 0.004 & -0.006 & $-0.009^{* *}$ & -0.005 \\
\hline & $(0.005)$ & $(0.005)$ & $(0.004)$ & $(0.004)$ \\
\hline Staff Age (Years) & -0.025 & $-0.097^{* *}$ & $0.116^{* *}$ & $0.165^{* * *}$ \\
\hline & $(0.051)$ & $(0.047)$ & $(0.045)$ & $(0.043)$ \\
\hline Staff With Degree (\%) & $-0.014^{* *}$ & -0.007 & 0.007 & $0.011^{* *}$ \\
\hline & $(0.006)$ & $(0.006)$ & $(0.005)$ & $(0.005)$ \\
\hline Full-Time Staff (\%) & 0.006 & $-0.019 * * *$ & 0.002 & 0.003 \\
\hline & $(0.007)$ & $(0.005)$ & $(0.005)$ & $(0.004)$ \\
\hline
\end{tabular}


Table B.2 - continued

\begin{tabular}{|c|c|c|c|c|}
\hline & Language & SocEmot & Motor & School \\
\hline Full-Time Children (\%) & $\begin{array}{c}0.001 \\
(0.001)\end{array}$ & $\begin{array}{c}0.000 \\
(0.001)\end{array}$ & $\begin{array}{c}0.003^{* * *} \\
(0.001)\end{array}$ & $\begin{array}{c}0.003^{* * *} \\
(0.001)\end{array}$ \\
\hline GDP per Capita & $\begin{array}{c}0.023^{* * *} \\
(0.006)\end{array}$ & $\begin{array}{l}0.011^{*} \\
(0.006)\end{array}$ & $\begin{array}{c}0.002 \\
(0.006)\end{array}$ & $\begin{array}{c}0.025^{* * *} \\
(0.006)\end{array}$ \\
\hline Female Employment Rate (\%) & $\begin{array}{c}0.019^{* *} \\
(0.009)\end{array}$ & $\begin{array}{c}0.009 \\
(0.007)\end{array}$ & $\begin{array}{c}0.001 \\
(0.007)\end{array}$ & $\begin{array}{c}0.006 \\
(0.007)\end{array}$ \\
\hline Unemployment Rate (\%) & $\begin{array}{c}0.003^{* * *} \\
(0.001)\end{array}$ & $\begin{array}{l}-0.001 \\
(0.001)\end{array}$ & $\begin{array}{c}0.001 \\
(0.001)\end{array}$ & $\begin{array}{c}0.001 \\
(0.001)\end{array}$ \\
\hline Log Children in County 0-2 Years & $\begin{array}{c}-1.176^{* * *} \\
(0.248)\end{array}$ & $\begin{array}{c}-1.089^{* * *} \\
(0.216)\end{array}$ & $\begin{array}{c}-0.998^{* * *} \\
(0.210)\end{array}$ & $\begin{array}{c}-1.237^{* * *} \\
(0.219)\end{array}$ \\
\hline Migration Rate (\%) & $\begin{array}{c}0.003 \\
(0.002)\end{array}$ & $\begin{array}{c}0.003^{*} \\
(0.002)\end{array}$ & $\begin{array}{c}0.002 \\
(0.002)\end{array}$ & $\begin{array}{c}0.003 \\
(0.002)\end{array}$ \\
\hline Log Children in School District Cohort & $\begin{array}{l}-0.009 \\
(0.013)\end{array}$ & $\begin{array}{l}-0.006 \\
(0.013)\end{array}$ & $\begin{array}{c}0.008 \\
(0.011)\end{array}$ & $\begin{array}{c}0.017 \\
(0.012)\end{array}$ \\
\hline Age (Avg) & $\begin{array}{c}-0.007^{* *} \\
(0.003)\end{array}$ & $\begin{array}{c}-0.007 * * * \\
(0.002)\end{array}$ & $\begin{array}{c}-0.012^{* * *} \\
(0.002)\end{array}$ & $\begin{array}{c}-0.008^{* * *} \\
(0.002)\end{array}$ \\
\hline Boys (Fract) & $\begin{array}{l}-0.052 \\
(0.042)\end{array}$ & $\begin{array}{l}-0.011 \\
(0.036)\end{array}$ & $\begin{array}{c}0.009 \\
(0.038)\end{array}$ & $\begin{array}{l}-0.032 \\
(0.033)\end{array}$ \\
\hline Low Birth Weight (Fract) & $\begin{array}{l}-0.079 \\
(0.080)\end{array}$ & $\begin{array}{l}-0.049 \\
(0.065)\end{array}$ & $\begin{array}{l}-0.027 \\
(0.064)\end{array}$ & $\begin{array}{l}-0.028 \\
(0.056)\end{array}$ \\
\hline Foreign (Fract) & $\begin{array}{c}0.006 \\
(0.069)\end{array}$ & $\begin{array}{c}-0.150^{* *} \\
(0.058)\end{array}$ & $\begin{array}{c}-0.091^{*} \\
(0.052)\end{array}$ & $\begin{array}{c}-0.112^{* *} \\
(0.052)\end{array}$ \\
\hline Number of Siblings (Avg) & $\begin{array}{c}0.015 \\
(0.026)\end{array}$ & $\begin{array}{c}0.007 \\
(0.019)\end{array}$ & $\begin{array}{c}0.040^{* *} \\
(0.018)\end{array}$ & $\begin{array}{c}0.004 \\
(0.016)\end{array}$ \\
\hline Single Mothers (Fract) & $\begin{array}{c}0.048 \\
(0.084)\end{array}$ & $\begin{array}{l}-0.023 \\
(0.063)\end{array}$ & $\begin{array}{l}-0.020 \\
(0.059)\end{array}$ & $\begin{array}{c}-0.094^{*} \\
(0.055)\end{array}$ \\
\hline Mother Has Tertiary Education (Fract) & $\begin{array}{c}0.118^{* *} \\
(0.052)\end{array}$ & $\begin{array}{c}0.062 \\
(0.048)\end{array}$ & $\begin{array}{c}0.015 \\
(0.044)\end{array}$ & $\begin{array}{c}0.055 \\
(0.044)\end{array}$ \\
\hline Mother Education Missing (Fract) & $\begin{array}{c}0.039 \\
(0.030)\end{array}$ & $\begin{array}{c}0.001 \\
(0.024)\end{array}$ & $\begin{array}{l}-0.028 \\
(0.022)\end{array}$ & $\begin{array}{c}0.043^{*} \\
(0.023)\end{array}$ \\
\hline District Fixed Effects & Yes & Yes & Yes & Yes \\
\hline Individual Characteristics ( $\mathrm{p}$-value) & 0.956 & 0.313 & 0.577 & 0.268 \\
\hline Center Characteristics (p-value) & 0.051 & 0.448 & 0.027 & 0.085 \\
\hline Unobserved Characteristics ( $\mathrm{p}$-value) & 0.149 & 0.172 & 0.421 & 0.536 \\
\hline R-squared & 0.098 & 0.087 & 0.105 & 0.113 \\
\hline Children & 36381 & 36381 & 36381 & 36381 \\
\hline
\end{tabular}

Notes: Estimates in this table stem from a reduced-form estimation of all skill dimensions projected on the propensity score (third order polynomial), the full set of control variables (individual, care center, county, and school district characteristics), and the interactions between the propensity score and individual and care center features. We additionally control for a set of school district dummies. Inference is based on standard errors that allow for clustering at the school district level. The bottom of the table displays p-values of three statistical tests: 1. heterogeneity with respect to unobserved characteristics ("Unobserved $U_{D}$ "), 2. a test for heterogeneity with respect to individual characteristics ("Individual"), 3. a test for heterogeneity with respect to care center quality features ("Quality").

Source: school entrance examination, Schleswig-Holstein 2009-2011, our calculations. 